\title{
COVID-19 vaccine rollout: Examining COVID-19 vaccination perceptions and intention among nurses
}

\author{
Emilee T. Austin \\ etaustin@mix.wvu.edu
}

Follow this and additional works at: https://researchrepository.wvu.edu/etd

Part of the Medicine and Health Sciences Commons, and the Social and Behavioral Sciences

\section{Commons}

\section{Recommended Citation}

Austin, Emilee T., "COVID-19 vaccine rollout: Examining COVID-19 vaccination perceptions and intention among nurses" (2021). Graduate Theses, Dissertations, and Problem Reports. 8284.

https://researchrepository.wvu.edu/etd/8284

This Thesis is protected by copyright and/or related rights. It has been brought to you by the The Research Repository @ WVU with permission from the rights-holder(s). You are free to use this Thesis in any way that is permitted by the copyright and related rights legislation that applies to your use. For other uses you must obtain permission from the rights-holder(s) directly, unless additional rights are indicated by a Creative Commons license in the record and/ or on the work itself. This Thesis has been accepted for inclusion in WVU Graduate Theses, Dissertations, and Problem Reports collection by an authorized administrator of The Research Repository @ WVU. For more information, please contact researchrepository@mail.wvu.edu. 
COVID-19 vaccine rollout: Examining COVID-19 vaccination perceptions and intention among nurses

\author{
Emilee T. Austin
}

Thesis submitted

to the Eberly College of Arts and Sciences

at West Virginia University

in partial fulfillment of the requirements for the degree of

Master's of Arts
in

Communication Theory and Research

Daniel Totzkay, Ph. D., Chair

Megan R. Dillow, Ph.D.

Christine E. Rittenour, Ph.D.

Department of Communication Studies

Morgantown, West Virginia

2021

Keywords: COVID-19, vaccine hesitancy, uncertainty, healthcare providers, nurses Copyright 2021 Emilee T. Austin 


\begin{abstract}
COVID-19 vaccine rollout: Examining COVID-19 vaccination perceptions and intention among nurses

Emilee T. Austin

Nurses' COVID-19 vaccination rates have been reportedly low for being among the first prioritized for vaccination. To understand and potentially explain uptake barriers, this thesis utilized the 5c Model, the Integrative Model, the Extended Parallel Process Model, Uncertainty Management Theory, and the Theory of Motivated Information Management. This project used an online survey with a convenience sample recruited through the WV Nurses Association. Specifically, there were 328 nurses recruited, then screened for fully vaccinated participants leaving an analytic sample of 174 West Virginia nurses who had not yet been vaccinated. Participants were asked about their nursing role, threat perceptions, susceptibility perceptions, efficacy perceptions, negative affect towards COVID-19, attitudes about COVID-19 and COVID-19 vaccination, information behaviors, trust in information sources, vaccination social norms, nursing identity, vaccination plans, and demographics. The findings portray norms having influence over intention to vaccinate and was further evaluated through levels of fusion to the nursing identity group. These findings were discussed in terms of the role of uncertainty within vaccination decision-making and how identity influenced vaccination intention with recommendations as to how to use these findings as well as future directions for research.
\end{abstract}




\section{TABLE OF CONTENTS}

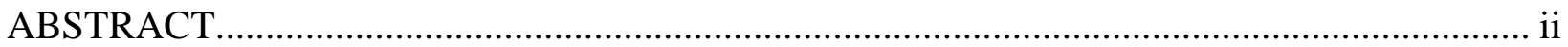

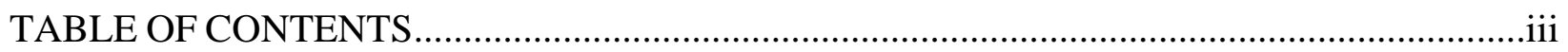

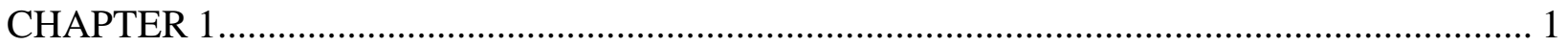

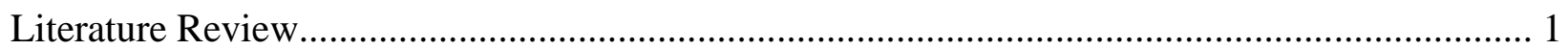

Introduction..................................................................................................... 1

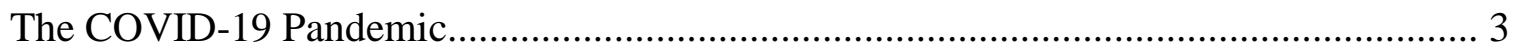

Healthcare Workers in the Pandemic............................................................... 5

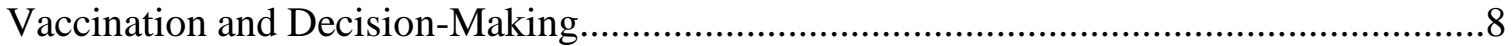

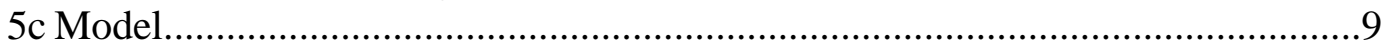

The Integrative Model............................................................................ 10

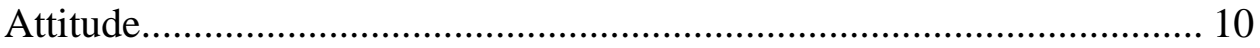

Perceived norms............................................................................ 11

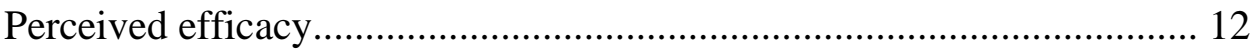

The Extended Parallel Process Model.............................................................. 13

Perceived threat........................................................................... 14

Perceived efficacy..................................................................... 14

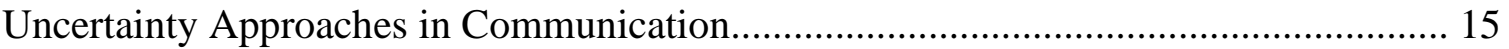

Integrating uncertainty in vaccination decision-making................................. 18

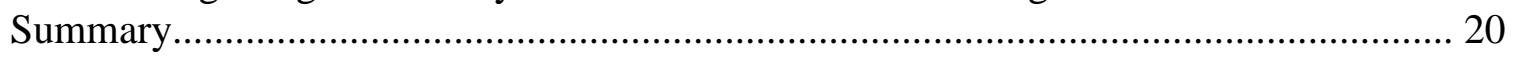

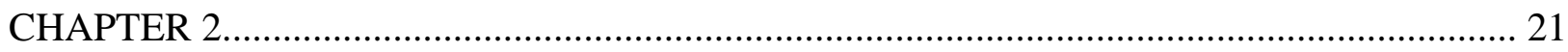

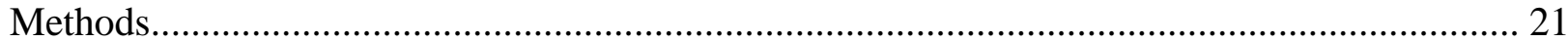

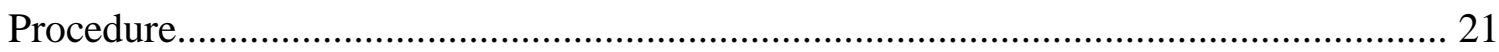

Participants and Recruitment............................................................................. 21

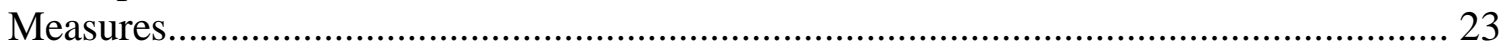

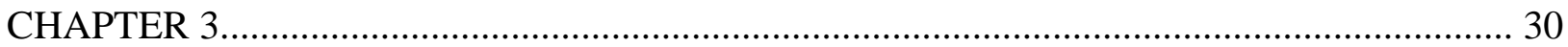

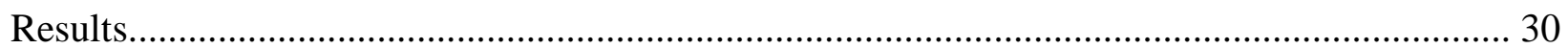

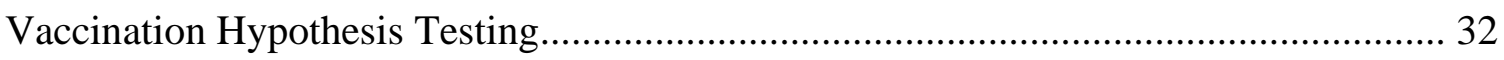

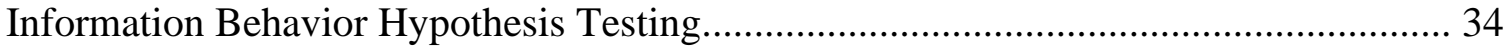

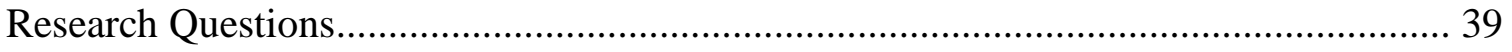

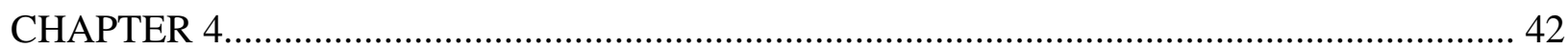

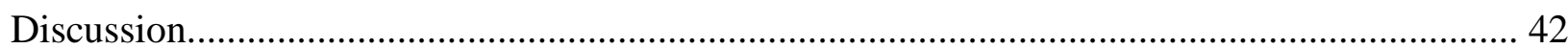

Uncertainty in Vaccination Decision-Making...................................................... 44

Identity, Social Norms, and Vaccination Decision-Making...................................... 46

Theoretical Implications................................................... 48

Recommendations for COVID-19 Messaging........................................................ 48

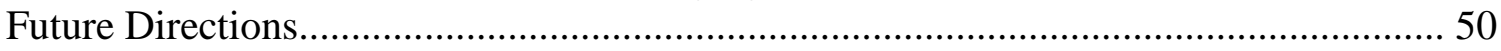

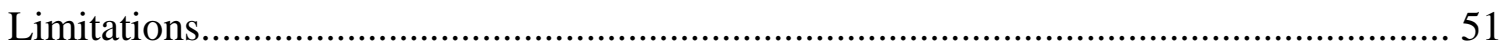

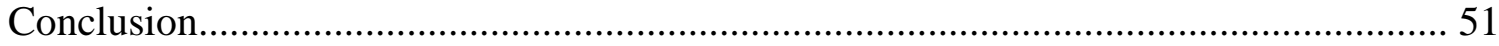




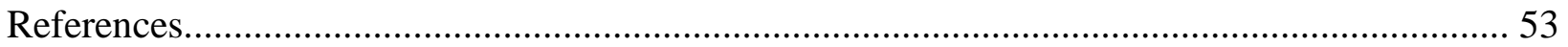




\section{CHAPTER ONE}

As of Spring 2021, there have been over 130,000,000 confirmed cases of the SARS-CoV2 Disease 2019 (COVID-19), including nearly 3 million deaths globally as reported by the World Health Organization (2021) and the Centers for Disease Control and Prevention (2021). In the United States (U.S.) alone, there are over 30,000,000 confirmed COVID-19 cases and over 500,000 deaths (World Health Organization, 2021; Centers for Disease Control and Prevention, 2021). As the pandemic continues, new variants of the virus that causes COVID-19 are occurring that make the virus easier to spread (Zimmer et al., 2021), and leveraging public health tools to contain the virus, mitigate disease, and eventually end the pandemic is critical.

Healthcare professionals have been crucial to fighting the COVID-19 pandemic from the start and have been at heightened risk of exposure to the virus that causes COVID-19 and severe COVID-19 illness. As three vaccines have been authorized for use in the U.S. and are being released to the highest priority persons, healthcare providers among them (Dooling et al., 2021), it is vital that accurate and relevant information is provided to encourage these individuals to get vaccinated when vaccines are made available to them. With the supply of vaccines and their nationwide distribution continuing to be sporadic (The New York Times, 2021, April 17), it creates uncertainty about the availability of the COVID-19 vaccines even for those that need it most. Uncertainty became the main theme of the COVID-19 pandemic as many messages about preventative care were unclear as well as what to do if one should contract the virus. In addition to unclear messages, there has been a large deal of misinformation about the virus and now about vaccines and their effectiveness (Chou et al., 2020). As a result, confidence in COVID-19 vaccines and the protection they can provide continues to be undermined. As the virus continues to spread, more knowledge is being gained about it, but uncertainty still looms. In order to ensure 
vaccination and other protective behaviors are enacted, the degree and nature of that uncertainty must be understood and messaged to accordingly.

As the rollout of COVID-19 vaccines continues, there are reports of some healthcare providers being either opposed to or uncertain about whether they will get vaccinated against the virus that causes COVID-19. Of special focus for this study is that nurses have been observed as substantially less likely to accept the new COVID-19 vaccines (Dror et al., 2020; Shaw et al. 2021). This difference in vaccination intention has also been observed for nurses' perceptions of the influenza vaccine (i.e., the flu shot) (del Carmen Anguilar-Diaz, Jiménez-Corona, \& Poncede-León-Rosales, 2011). In order to protect this population and ensure wide-scale adoption of COVID-19 vaccination, the reasons behind nurses' reluctance or apprehension toward vaccination need to be better understood and addressed through strategic messaging. These concepts are generally covered under the umbrella of vaccine hesitancy, which overlaps with more concrete conceptualizations of behavior change and social influence models used in Communication Studies, including the Integrated Model of Behavioral Prediction and the Extended Parallel Process Model. Healthcare providers are often not the focus of studies around vaccine hesitancy, so delineating their unique perceptions in this context will provide great benefit to the ongoing public health response.

However, both vaccine hesitancy as a concept and social influence theories leave out an important concept central to other models in Communication: uncertainty and its management. The experience of uncertainty will vary based off the individuals desired level or tolerance to ambiguity. However, when these levels of uncertainty become a factor within a decision it is unclear how people use, experience, manage, or diminish uncertainty. With the state of public health concerns being naturally ambiguous, it is vital to understand what role uncertainty plays in 
vaccination decisions, especially within the context of COVID-19 vaccines. Vaccination decision making has considered the known apprehensions that vaccination carries, but not as broadly as uncertainty around the virus and consequently the vaccine.

This thesis aims to explore nurses' decision-making around COVID-19 vaccination, with a specific focus on the role of uncertainty both about the pandemic and available vaccines. In what follows, this study first reviews the state of the COVID-19 pandemic, and specifically the U.S. experience, with special attention to the role of nurses. Then, vaccination decision-making models are explained and tied to commonly-applied theoretical models in the communication field. Then, a case is made for why the communicative study of uncertainty needs to be integrated into vaccination decision-making, especially during situations like the COVID-19 pandemic and the ensuing vaccine rollout. Finally, a study is proposed that aims to examine nurses' current decision-making around vaccination and study the role of uncertainty within those processes.

\section{The COVID-19 Pandemic}

The first reported case of COVID-19 was in Wuhan, China, on January 11th, 2020 (Taylor, 2020). Nine days later, on January 20th, 2020 the first case of COVID-19 was confirmed in the U.S. from a traveler who had recently returned from Wuhan. However, this virus prosed a special challenge because little was known about the novel virus and available or established medical technology could not properly combat it. By February 24th, 2020 there were large spikes in cases in Italy followed by Iran (Taylor, 2020), and it quickly became apparent that routine solutions were not mitigating the rise of the virus. It was later declared a pandemic in March 2020. 
As the coronavirus continued to spread and more was learned about it, various health organizations began to put out recommendations about how to properly protect yourself and others. Early recommendations for protection measures were often limited or unclear, such as suggested that wearing a mask was not necessary or even at times discouraged, social distancing was suggested but not mandated, and travel bans were not heavily enforced if proposed at all (Taylor, 2020). With these limited measures, uncertainty about the severity of the COVID-19 began to circulate (e.g., if it were so serious, there would be more hardline restrictions). As time went on, and the case numbers continued to rise, the severity of the COVID-19 virus became more apparent, and further protections measures were implemented.

Before the end of March 2020, the U.S. ranked highly in reported cases and deaths and quickly outpaced other highly-infected countries like Italy and India (Taylor, 2020). With some new information and high infection rates the virus was slightly better understood, so wearing a mask and social distancing began to take a larger precedent. As new information continued to become available guidelines continuously changed, resulting in creating uncertainty around the virus and how to properly protect yourself as well as others. Around this same time travel bans, and quarantine began to be taken seriously. July $10^{\text {th }}, 2020$ marked record setting spikes in case numbers, the United States set the single-day record in cases seven times within eleven days and in just one day there was 68,000 new confirmed cases of COVID-19 (Taylor, 2020). As the virus continued to grow, quarantine became more necessary, and business began to close their doors to assist in reducing the spread of the virus as well as not being able to keep them open.

Nearly a year after the first case of COVID-19 was diagnosed, COVID-19 vaccines began to be distributed worldwide. In the U.S., the Food and Drug Administration has authorized three vaccines for use in the country, two requiring a double dose and using newer mRNA 
technology and the third using more traditional methods and requiring only a single dose (CDC, 2021). Vaccination is critical to stopping the pandemic, primarily through establishing herd immunity (Erzurum, 2021), meaning that enough people are vaccinated so the virus cannot spread throughout the population at scale. To reach herd immunity, the number or percent of the population is not certain either, but it could require between 50 to 80 percent of the population to become vaccinated to mitigate the spread of the virus (Erzurum, 2021). However, this requires massive investment not only in distribution infrastructure, but also in research around how best to encourage Americans to get vaccinated. Doing this quickly and equitably is critical not only to protect the population in general, but especially given the rise of new variants of the virus that is causing uncertainty around the effectiveness of the available vaccines (Zimmer et al., 2021).

\section{Healthcare Workers in the Pandemic}

Healthcare workers have been among the first priority groups to be offered COVID-19 vaccinations nationwide in order to protect these professionals at heighten risk for COVID-19 illness and to ensure the healthcare infrastructure remain intact as the pandemic continues as mentioned by the CDC (2021). Within healthcare providers generally, it is crucial to focus specifically on vaccination of nurses. Since the beginning of the COVID-19 pandemic, nurses have especially been put at extreme risk with shortages of personal protective equipment (Caroselli, 2020), in addition to separation from loved ones and the extreme rates of patient deaths (Sethi et al., 2020). This workforce is essential to effectively impeding the growth of the COVID-19 virus, it is vital to emphasize their importance as a main resource of security and insurance for ending the pandemic. Adding to this is the unfortunate reality that nurses as a profession are being observed as less likely to pursue COVID-19 vaccination (Dror et al., 2021). The reasons for this are unclear, given a lack of research on healthcare provider vaccine 
perceptions and very little social science research in general around COVID-19 vaccination specifically.

The professional identity of a nurse may influence how nurses view COVID-19 vaccines. Nurses have low levels of control over their work environment and a power imbalance within the workplace setting. Identity can be understood as the values, beliefs, and associations one has about themselves in reference to the social groups to which they belong. Allport (1954) suggested that when there is group membership, there is the opportunity for power dynamics to develop, in which one group exerts power over the other. In general, the majority group is seen as superior to the minority group regardless of group membership because of its prominence. Marginalized groups are known to have four commonalities including 1) the majority group benefiting from the marginalization of the minority group, 2 ) the minority group developing negative views of their own group, 3) shifts in these views develop out of dissonance, and 4) there must be a stimulus to encourage the cognitive processing of developing alternative views that cause dissonance to occur (Helms \& Cook, 1999). There are multiple forms of oppression when developing an identity within a marginalized group, or there are parts of their life that are diminished (Salazar, 2005). The crux of identity development within a marginalized group is the resistance of marginalization because it requires advocating for the group to which they belong (Salazar, 2005). Nurses are an oppressed group within the medical field because they are held in a lesser regard than physicians, and the profession is also dominated by the female gender which is another oppressive association. Within the context of COVID-19 specifically, there is heightened risk of exposure, contraction, and fear, all of which further oppress nurses' roles and highlight the lack of control that they have. While nurses may not be seen as a typical marginalized group, it must not be forgotten that each marginalized group will face similar but 
different experiences throughout their group membership that create their marginalization (Allport, 1954). However, identifying with that group does not mean that the individual cannot identify with another group. When an identity is salient that means that is highly important in that moment, but identities do not necessarily compete as some may complement each other (Swann et. al., 2009). When discussing group membership, it is worth noting that professional identity can shape personal identity and that identity salience is contextual (Willets \& Clark, 2014). If the identities do complement each other they may work in tandem to reinforce the ideologies and values of both groups to which they belong, this can result in extreme behavior or willingness to act in accordance with the groups goals (Swann et. al., 2009). Aligned with Social Identity Theory, people identify with a group based on self-categorization and in-group behavior (Willets \& Clark, 2014), simply meaning that group membership is socially constructed through the individual's perception of their standing within the group. In connection to vaccine decisionmaking, it is possible that the extent to which nurses view themselves as part of a "nurse" social group can affect how they view and navigate uncertain and new vaccines and the pandemic at large. If nurses view themselves as truly embedded within that social group, internalization of their marginalized status may occur that can result in reluctance to get vaccinated or otherwise affect social dynamics around vaccine communication. The role of identity has not been explored in the realm of vaccine decision-making previously, but given the observed group differences in vaccination intention in nurses (Dror et al., 2021), this may provide some explanation or insight into why nurses differ in motivation.

RQ1: How does the extent to which nurses view nursing as a part of their identity affect their vaccine decision-making? 
Overall, when it comes to vaccination decision-making, many behavioral theories are available to help understand the motivations and psychosocial circumstances of the people counted on to protect society and provide actionable, accurate, and relevant information to inform their vaccination decision-making. Without the dedication of the nursing workforce the healthcare system would face detrimental failures as a result of the pandemic. Furthermore, by enhancing vaccination rates and confidence among nurses, they can be relied on to boost vaccination among the general public given their place as consistently trusted sources of medical information and the high frequency at which individuals interact with them, relative to other healthcare professionals (Clayton \& Ellington, 2011; Silk et al., 2019).

\section{Vaccination and Decision-Making}

The World Health Organization (https://www.who.int/) characterizes vaccination as one of the most cost-effective, safe, and reliable methods of reducing disease, death, disability, and inequity worldwide (Andre, Booy, Bock, et al, 2008). However, vaccines are widely misunderstood medicines, and the idea of a vaccine could be intimidating to some, which is often captured under the umbrella term of "vaccine hesitancy." The SAGE Working Group on Vaccine Hesitancy concluded that vaccine hesitancy refers to delay in acceptance or refusal of vaccination despite availability of vaccination services (MacDonald, 2015). The concept of vaccine hesitancy occurs on a continuum, ranging from fully intending to get vaccinated to being completely opposed to vaccination (Bedford et al., 2017). This means that individuals can be more or less "hesitant" and thus more or less supportive of vaccination. Vaccine hesitancy can be partially understood through the term decisional conflict, which describes the paradox of existing in an uncertain or undetermined state and widely used to understand vaccination behavior (Bedford et al., 2017). In the following sections, vaccine hesitancy is first explicated in terms of 
establish psychosocial theories of behavioral decision-making, and then extended with a focus on uncertainty.

\section{C Model}

The most holistic conceptualization of vaccine hesitancy comes from the 5C Model of Vaccine Hesitancy and proposed by Bestch et al. (2018). While vaccine hesitancy has been defined generally as above, it can be sorted into discrete dimensions that aids in measurement and message targeting. These dimensions in the 5C Model include confidence, constraints, complacency, calculation, and collective responsibility (Bestch et al., 2018). Each is briefly described here to draw connections between this model that is more oriented toward public health and medical practitioners and models more typical in social science research and specifically Communication Science.

The 5C model generally predicts that individuals are more likely to pursue vaccination when they have confidence in the respective vaccine, meaning that they trust the respective vaccines' effectiveness and safety. Further, they are more likely to pursue vaccination with fewer perceived constraints, which are personal barriers that may lie in the way of getting vaccinated such as physical availability, affordability, geographical accessibility, and health literacy. Next, it is predicted that vaccination is less likely to occur as an individual increases in the third " $\mathrm{C}$," complacency, which in this case refers to believing there is minimal risk to contracting the disease and the vaccine being deemed unnecessary. The forth "C" that predicts vaccination is calculation, which refers to persons' involvement in information seeking, predicting that more information seeking will lead to a more informed vaccination decision (Bestch et al., 2018). Finally, the fifth "C" refers to collective responsibility, in this context meaning that a person is 
more likely to pursue vaccination when they are more willing to shield others through their own vaccination, including the influence of normative pressure from one's peers.

\section{The Integrative Model}

Given the nature and motivations of models like the 5C Model, the concepts are not necessarily concrete psychosocial constructs and might not be as informative for strategic messaging. Theoretical models in Communication Science are often applied to understand how and when individuals adopt various types of behaviors and inform strategic messaging to promote behaviors like vaccination. Among the most established models is the Integrative Model. As described by Yzer (2012a), the model predicts that a person's behavioral intention is the best-known indicator of behavior and is defined by the individual's preparedness or likelihood to enact a specific behavior. In other terms, intention can be understood simply as the commitment to performing a behavior, or the commitment to get vaccinated when vaccination becomes available to them (Cowling, So, Ip, \& Liao, 2019). Intention within this study specifically refers to nurses' degree of commitment to getting vaccinated against the virus that causes COVID-19. The Integrated Model details how variables such as attitude, perceived norms, and self-efficacy to predict the intention that an individual has about the behavior (Yzer, 2012a). In what follows, each of these predictors of behavioral intention are defined and connected to conceptualizations of vaccine hesitancy.

Attitude. An attitude is a complete analysis of behavior and can vary in strength as suggested by Ajzen (2001), having a positive or negative valence and can vary in accessibility. Strong attitudes tend to remain consistent over time and are reliable predictors of behavior (Ajzen, 2001). Attitude reflects the values and beliefs an individual may hold, here specifically the values and beliefs held towards the COVID-19 vaccine. The Integrative model includes two 
classes of attitudes: affective attitudes and instrumental attitudes. An affective attitude is the positive or negative affective or emotional associations that an individual has about the behavior in question (Lukacena et al., 2017). Specific to this study, nurses' affective attitudes would refer to considering COVID-19 vaccination as good or bad, with vaccination intention increasing as they felt more positively about it. Instrumental attitudes, on the other hand, are the cognitive consequences of the behavior, meaning that this type of attitude takes into account perceptions of whether the behavior is successful in mitigating risk or achieving a preferred outcome (Lukacena et al., 2017). Specific to this study, nurses' instrumental attitudes are in reference to whether they view COVID-19 vaccination as effective in mitigating the spread of COVID-19 and protecting themselves from contracting the virus of COVID-19. In this case, the more that nurses think they are protected by COVID-19 vaccination, the more likely it is that they pursue vaccination. Attitude, and especially instrumental attitude, closely resembles the "confidence" dimension of the $5 \mathrm{C}$ Model of vaccine hesitancy.

H1: Nurses' vaccination intention will be positively predicted by their a) affective attitude, and b) instrumental attitude.

Perceived norms. Within this model perceived norms are a collection of beliefs that fall into two categories, subjective, descriptive, and injunctive norms (Park \& Smith, 2007). Subjective norms are associated with social pressure derived from the social networks that an individual may belong to (Yzer, 2012a). These norms typically result in submission or nonconformity to the social influence (Lukecena et al., 2017), and reflect the perception that one "should" or "should not" do a behavior. In the case of COVID-19 vaccination, the subjective norm refers to a nurse's perception that others important to them think they should get vaccinated. Descriptive norms, on the other hand, refer to how frequent a behavior is perceived 
to be (Yzer, 2012a). These norms can be considered similar to a heuristic that assist in guiding a person's actions, helping to determine what would be helpful and appropriate during a given circumstance. For COVID-19 vaccination, as nurses perceive that more people who are important to them are pursuing COVID-19 vaccination, the more likely they will do the same. Lastly, injunctive norms refer to the perception that important others approve of a given behavior, like getting vaccinated. In this case, the more that nurses believe that people important to them approve of them getting vaccinated (or, would disapprove of them not getting vaccinated), the more they would plan to get vaccinated themselves. Perceived norms generally reflects aspects of the "collective responsibility" dimension of the 5C Model of vaccine hesitancy (see Bestch et al., 2018).

H2: Nurses' vaccination intention will be positively predicted by their a) subjective, and b) descriptive, c) injunctive norms.

Perceived efficacy. The third major component of the Integrative Model is the prediction of behavioral intention by perceptions of efficacy. Specifically, it is predicted that a behavior is more likely to be planned when an individual perceived greater self-efficacy and behavioral control (Yzer, 2012a). Perceived self-efficacy refers to how much the individual believes they can actually perform the behavior (Yzer, 2012a). These beliefs help guide the individual through how comfortable and confident they feel about performing the behavior, with individuals estimating their ability to perform the behavior based on these beliefs. Perceived self-efficacy in this context refers to nurses' perceived ability to get vaccinated against the virus that causes COVID-19. While capacity is associated with self-efficacy or the capability to perform the action, autonomy is associated with control over the action (Yzer, 2012b). The other component of the perceived efficacy construct in the Integrated Model is perceived behavioral control, 
which refers to the amount of control an individual feels they have over executing a behavior (Ajzen, 2002). The perception is stemmed from control beliefs about the behavior, so if the induvial believes that they can or they do have control then there is greater likelihood that they will complete the action (Yzer, 2012b). An individual is considered to have control over a behavior when they have the proper skills to perform that behavior (Yzer, 2012b). Within this study, control is viewed as whether nurses believe they have the skills to get a COVID-19 vaccine or that getting vaccinated is something they personally have control or power over. The concept of perceived efficacy generally aligns with the 5C Model's concept of "constraints." H3: Nurses'vaccination intention will be positively predicted by a) perceived behavioral control, and b) self-efficacy.

In summary, the Integrated Model more concretely details various components of vaccine hesitancy models and can be readily applied to understand nurses' reasons for or against COVID-19 vaccination. However, some components of the Extended Parallel Process Model may offer further insight to how the components of perceived threat relate to vaccination decision making.

\section{The Extended Parallel Process Model}

The Extended Parallel Process Model (EPPM) portrays decision-making around risks to one's health and well-being. The EPPM has four basic components including severity, susceptibility, self-efficacy, and response efficacy, these components will decide how effective the persuasive attempt is as explained by Basil and Witte (2012). The components of severity and susceptibility are what the individual uses to determine the level of threat that a certain behavior poses which in turn decides if it is necessary to act on. The other two components of 
self-efficacy and response efficacy are what determines if the individual will perform the response behavior.

Perceived threat. Central to the EPPM's prediction of precaution decision-making is that an individual must perceive a risk to be sufficiently threatening before they will act to protect themselves (Popova, 2012). Perceived threat of can be explained through the two dimensions of perceived susceptibility and perceived severity. Perceived susceptibility is defined as the perceived likelihood that a person will encounter the health hazard (Basil \& Witte, 2012). In relation to COVID-19, perceived susceptibility is the chance, or likelihood that a person believes they will contract the virus and develop COVID-19. Perceived severity, on the other hand, can be explained by the seriousness of the consequences caused by the health risk (Basil \& Witte, 2012). In relation to COVID-19, the perceived severity can be explained as the potential impact the virus may have on the individual, or the degree of potential suffering from the virus. Finally, perceived threat encompasses the feeling of negative emotions such as fear and worry, which are related to both perceived severity and susceptibility, and seen as a motivational drive that can lead to enacting precautionary behaviors in risk settings (Popova, 2012). Perceived threat overall resembles the "complacency" dimension of the 5C Model of vaccine hesitancy, in that when threat perceptions are low for a vaccine-preventable disease, vaccination intention is likely to be low. Overall, nurses should then be more likely to plan to get vaccinated when they perceive that COVID-19 is an adequate threat.

H4: Nurses' vaccination intention will be positively predicted by their a) perceived severity, $b$ ) perceived susceptibility, and c) negative affect.

Perceived efficacy. Perceived efficacy is the way an individual believes that they have the capability of controlling and preventing an unfavorable consequence and can be understood 
through two types of efficacy such as self-efficacy and response efficacy (Basil \& Witte, 2012). Self-efficacy is the confidence an individual has about their ability to do a suggested action (Basil \& Witte, 2012), and is closely aligned with the perceived self-efficacy dimension of the Integrated Model explained above. Response efficacy, on the other hand, is the confidence an individual has about that action providing them protection against the risk (Basil \& Witte, 2012). In other words, response efficacy is the perception of how effective a protective behavior is in actually protecting oneself. This concept is also closely aligned to especially the instrumental attitude dimension of the Integrated Model detailed above. What perceived efficacy in terms of the EPPM looks like in this context is that if a nurse wanted to get a COVID-19 vaccine, they would need to believe that they can actually get vaccinated and that vaccination will protect them against the virus that causes COVID-19.

H5: Nurses' vaccination intention will be positively predicted by their perception of response efficacy.

\section{Uncertainty Approaches in Communication}

Uncertainty reduction theory is a foundational communication theory that helps to explain how individuals experience uncertainty. Berger and Calabrese (1975) proposed the original uncertainty reduction theory about human interaction being motivated through wanting to reduce uncertainty. Uncertainty management theory is derived from uncertainty reduction theory, positing that people do not always reduce their uncertainty and instead they use strategies to cope and manage the levels of uncertainty that they have. As described by Brashers (2001), uncertainty management theory suggests that being uncertain is a self-perception, one thinks that they are uncertain. Uncertainty can be derived through cognition, though knowledge is not necessarily a direct link to uncertainty. A person can still have ample knowledge within a given 
domain and be uncertain about it (Brashers, 2001). Uncertainty Management Theory posits that levels of uncertainty are highest when there is a greater probability of the occurrence happening while uncertainty levels descend as the probability descends (Brashers, 2001). Context is an important factor in uncertainty management because people have many locations of context, be it internal or external (Brashers, 2001). One important dimension of uncertainty is that it is temporal, varying from short-term uncertainty to ongoing uncertainty (Brashers, 2001). Ongoing uncertainty is compared and associated with chronic illness and long periods of time in a person's life in which they may experience uncertainty (Brashers, 2001). In addition, peer and family support are the most influential for managing uncertainty both positively and negatively for chronic conditions (Brashers et al., 2004). It is important to note that managing uncertainty implies that while some may find uncertainty uncomfortable and want to be rid of it, others might actually desire uncertainty. This concept is explored further in the Theory of Motivated Information Management (Afifi \& Weiner, 2004), which predicts that it is not just uncertainty that is motivation, but instead a discrepancy between how much a person wants to know about an issue and how much they actually know. This might result in wanting to know more information, which would resemble previous conceptualizations of uncertainty, or in wanting to know less (or, increasing uncertainty).

Behaviors are motivated that can manage this difference in information, either ones that involve searching for new information to increase certainty or knowledge of an issue, or that help individuals maintain or decrease their level of certainty by avoiding information all together. Information avoidance occurs when an individual perceives that finding out more information will be unpleasant or cause discomfort. As described by Case et. al. (2005), an individual's tendency to avoid information is influenced by the salience or personal relevance of the health 
risk. Some individuals may choose to avoid information because of the fear of confirming poor outcomes (Case et. al., 2005). While information seeking occurs when an individual perceives that finding out more information will be useful or beneficial. As discussed by Turner et. al. (2006), risk perceptions have different degrees of intensity for each individual and for those individuals that have stronger efficacy beliefs about finding beneficial information they will be more likely to seek out new information. However, when anxiety is present then efficacy beliefs do not motivate the act of information seeking only arouse the motivations cognitively (Turner et. al., 2006). Information seeking when the individual is experiencing anxiety may lessen the retention of the information that is found (Turner et. al., 2006). It should be, then, that not only do perceptions of risk and efficacy predict risk-reducing behaviors like vaccination, but they should also motivate behaviors like information seeking and avoidance (Turner et al., 2006), as should social norms and attitudes (Kahlor, 2010). The COVID-19 pandemic continues with a clear end being ambiguous, and thus likely to generate uncertainty, and has been compared to chronic conditions by the Fuchs et al. (2021). The period of ongoing, or chronic uncertainty is hopefully coming to an end through the release of COVID-19 vaccines, but may be perceived differently across individuals.

H6: Nurses' information seeking will be predicted by a) affective attitudes, b) instrumental attitudes, c) perceived severity, d) perceived susceptibility, e) negative affect, f) self-efficacy, $g$ ) perceived behavioral control, $h$ ) response efficacy, i) subjective norms, $j$ ) descriptive norms, and k) injunctive norms.

H7: Nurses' information avoidance will be predicted by a) affective attitudes, b) instrumental attitudes, c) perceived severity, d) perceived susceptibility, e) negative affect, f) self-efficacy, $g$ ) 
perceived behavioral control, $h$ ) response efficacy, i) subjective norms, j) descriptive norms, and k) injunctive norms.

Integrating uncertainty in vaccine-decision-making. When considering uncertainty within decision making, it could be suggested that a clearer conceptualization of vaccine hesitancy or different motivations to get vaccinated is in decisional conflict. Decisional conflict can be understood as a state of uncertainty in regard to performing a behavior as explained by Shourie et al. (2013). Similarly, the concept of uncertainty discrepancy refers to having a level of uncertainty that is different than the desired level (Afifi \& Weiner, 2006; Crowley et. al., 2020). Using this conceptualization allows for vaccine decision-making to be understood as a spectrum derived from the cognitions associated with performing a behavior. In addition, the use of the term hesitancy has become more common across popular media (Bedford et al., 2021), which could contribute to the uncertainty about vaccines and vaccination. Crowley et. al. (2020) reported that uncertainty discrepancy regarding COVID-19 positively relates to high levels of anxiety. Additionally, it was observed that uncertainty anxiety is positively associated with reevaluation of information, avoiding information, and seeking information in relation to COVID-19 (Crowley et. al., 2020). In all, there is likely a substantial uncertainty discrepancy about COVID-19 vaccines in terms of their safety and effectiveness, in addition to uncertainty about the risk posed by COVID-19 itself, which impacts individuals' likelihood of enacting protective behaviors and how information about COVID-19 and vaccines is approach. Taking an uncertainty approach can broaden how vaccine decision-making is conceptualized, and better incorporate decision-making models like the Theory of Motivated Information Management, the Integrated Model, and the EPPM. 
Uncertainty management has been synthesized with the EPPM, but was not supported empirically. The study in question examined how uncertainty surrounding bed bugs as a threat and toward protective behaviors impacted information management (Goodall \& Reed, 2013). These authors argued that uncertainty about a threat would lead to maladaptive message responses, such as avoiding risk information, as could uncertainty about whether a recommended response would effectively protect against the threat. As people may be more inclined to keep or manage their current level of uncertainty instead of addressing their concerns because of the chance of verification (Brashers, 2001), these feelings of uncertainty should reduce the chances that risk-reducing behavior like information seeking will take place. However, this study did not observe an effect of uncertainty on information behaviors. One reason for this is because uncertainty about a threat and the efficacy of a protective behavior should impact motivation not directly, but instead through perceptions of threat and efficacy (Totzkay, Silk, \& Thomas, 2020). This means that uncertainty about a threat and the efficacy of a protective behavior should decrease perceptions of threat and efficacy, respectively, which both positively predict behavioral intention. The state of effectiveness and safety perceptions of COVID-19 vaccines remain uncertain and would be positively benefitted from increased uptake to solidify the evidence of the vaccines' effectiveness and safety. In other words, the uncertainty centered around the solution (the vaccine) could be causing the decisional conflict, a discrepancy in uncertainty/information known, or experienced state of uncertainty that restricts vaccination intention. Likewise, there is an uncertainty discrepancy around the risk of COVID-19 in general, especially as more individuals are familiar with those who have cases of mild COVID-19 illness or have not had direct experience with COVID-19, which would result in less intention to take part in risk-reducing behaviors like getting vaccinated. 
H8a: Nurses' vaccination intention will be indirectly negatively predicted by need information (uncertainty) about the threat of COVID-19, mediated by COVID-19 threat perceptions.

H8b: Nurses'vaccination intention will be indirectly negatively predicted by need for information (uncertainty) about COVID-19 vaccination efficacy, mediated by COVID-19 vaccination efficacy perceptions.

H8c: Nurses' intention to seek COVID-19 information will be indirectly negatively predicted by need information (uncertainty) about the threat of COVID-19, mediated by COVID-19 threat perceptions.

H8d: Nurses' intention to seek COVID-19 information will be indirectly negatively predicted by need for information (uncertainty) about COVID-19 vaccination efficacy, mediated by COVID19 vaccination efficacy perceptions.

H8e: Nurses' avoidance of COVID-19 vaccine information will be indirectly negatively predicted by need information (uncertainty) about the threat of COVID-19, mediated by COVID19 threat perceptions.

H8f: Nurses' avoidance of COVID-19 vaccine information will be indirectly negatively predicted by need for information (uncertainty) about COVID-19 vaccination efficacy, mediated by COVID-19 vaccination efficacy perceptions.

\section{Summary}

In sum, this study aims to describe the nature of a nurses' decision to get the COVID-19 vaccine and conceptualize vaccine hesitancy as uncertainty. 


\section{CHAPTER TWO}

\section{Method}

\section{Procedure}

An online survey was distributed to nurses through the West Virginia Nurses Association. Participants were required to be a practicing nurse in the state of West Virginia and at least 18 years of age. First, after participants agree to be in the study, the survey will take approximately 15 minutes. The participants answered survey questions about COVID-19 vaccination intention and their perceptions about COVID-19, as well as demographic questions like sex, age, race, ethnicity, and years of experience. After completing the demographic questions, participants were routed to an external survey to collect contact information for delivery of their compensation.

\section{Participants and Recruitment}

A total of 328 West Virginia nurses completed the survey. Participants were screened for only those nurses who have not been fully vaccinated against the virus that causes COVID-19, resulting a final analytic sample of 174 participants. The average age of the sample was 34.85 years $(\mathrm{SD}=6.11)$, reporting an average of 8.94 years $(\mathrm{SD}=5.83)$ of nursing practice. Nurses largely identified as a woman ( $\mathrm{n}=137,78.3 \%)$, and mostly identified as being White/Caucasian $(\mathrm{n}=101,57.7 \%)$ or Black/African American $(\mathrm{n}=50,28.6 \%)$. Most participants reported being a Registered Nurse (RN; $\mathrm{n}=115,65.7 \%)$, and working in a combination of In-Patient settings $(\mathrm{n}=106,60.6 \%)$, Out-Patient Settings $(\mathrm{n}=55,31.4 \%)$, and Long-Term Care $(\mathrm{n}=89,50.9 \%)$. Table 1 shows a complete breakdown of participant demographic information. 
Table 1.

Analytic sample demographics

Sex/Gender

$\begin{array}{cc} & \mathrm{n}(\%) \\ \text { Man } & 38(21.7 \%) \\ \text { Woman } & 137(78.3 \%)\end{array}$

Race/Ethnicity

Asian/Asian American (East Asian)

$1(.6 \%)$

Asian/Asian American (South Asian)

$2(1.1 \%)$

Black/African American

$50(28.6 \%)$

Hispanic

$5(2.9 \%)$

Native American or Alaska Native

$14(8 \%)$

Native Hawaiian or Pacific Islander

$1(.6 \%)$

White/Caucasian

$101(57.7 \%)$

Middle Eastern

$1(.6 \%)$

Other

0

\section{Education}

Less than 9th grade

9th-11th grade (including 12th grade with no diploma)

High school graduate

GED or equivalent

Some college, no degree

Associate degree

Bachelor's degree

Master's degree

Professional degree (e.g., MD, DDS, DVM, JD)

Doctoral degree (e.g., $\mathrm{PhD}, \mathrm{EdD})$
$1(.6 \%)$

0

$2(1.1 \%)$

$2(1.1 \%)$

$10.9 \%$

$34.9 \%$

$49.1 \%$

0

$1(.6 \%)$

$2(1.1 \%)$ 


\begin{tabular}{|c|c|}
\hline Nursing Role & $\mathrm{n}(\%)$ \\
\hline Certified Nursing Assistant & $4(2.3 \%)$ \\
\hline Licensed Practical Nurse & $9(5.1 \%)$ \\
\hline Advanced Practice Registered Nurse & $36(20.6 \%)$ \\
\hline Registered Nurse & $115(65.7 \%)$ \\
\hline Bachelor of Science in Nursing & $14(8.0 \%)$ \\
\hline Master of Science in Nursing & $2(1.1 \%)$ \\
\hline Doctor of Nursing Practice & $1(.6 \%)$ \\
\hline Nurse Educator of Professor & $1(.6 \%)$ \\
\hline Nurse Manager/ Nurse Executive & $2(1.1 \%)$ \\
\hline Clinical Nurse/Staff Nurse & $5(2.9 \%)$ \\
\hline Other Nursing Position & $2(1.1 \%)$ \\
\hline \multicolumn{2}{|l|}{ Specialty } \\
\hline In-Patient & $106(60.6 \%)$ \\
\hline Out-Patient & $55(31.4 \%)$ \\
\hline Long-term care & $89(50.9 \%)$ \\
\hline School/education & $4(2.3 \%)$ \\
\hline Home health & $23(13.1 \%)$ \\
\hline Corrections & $13(7.4 \%)$ \\
\hline Corporate/workplace & $2(1.1 \%)$ \\
\hline Public health & $29(16.6 \%)$ \\
\hline Administration & $4(2.3 \%)$ \\
\hline Other & $3(1.7 \%)$ \\
\hline
\end{tabular}

\section{Measures}

The following description of survey measures will present only sample items from each construct. Complete scale items can be found in Table 2. Unless otherwise noted all scales were scored on 7-point Likert-type scales (e.g., 1= strongly disagree, $7=$ strongly agree). 


\section{Table 2}

Scale Items

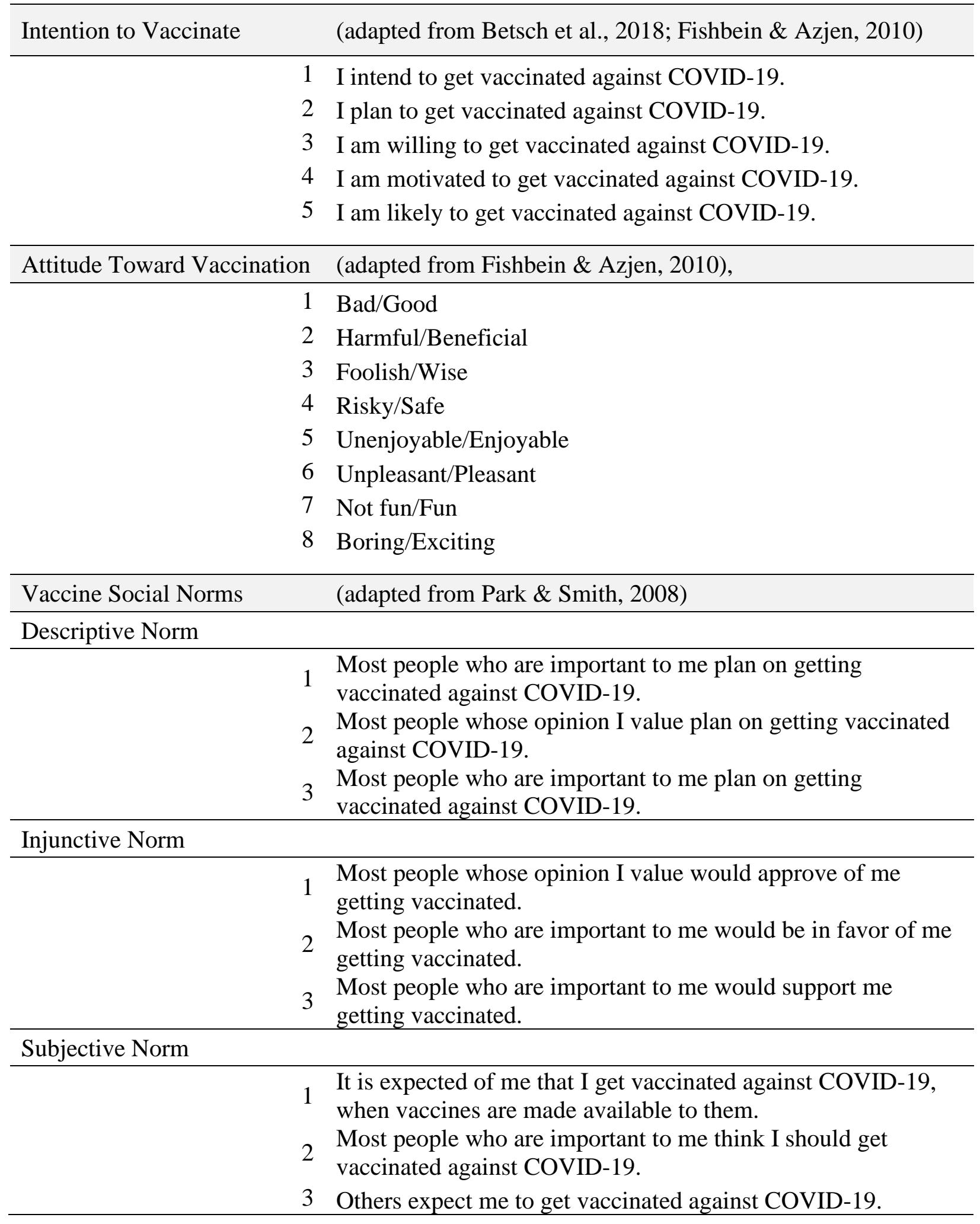


Table 2 Continued

\begin{tabular}{|c|c|c|}
\hline \multicolumn{3}{|l|}{ Vaccine Efficacy Beliefs } \\
\hline \multirow{4}{*}{ Vaccine Response Efficacy } & & (adapted from Witte et al, 1996) \\
\hline & 1 & $\begin{array}{l}\text { COVID-19 vaccination is effective in preventing COVID-19 } \\
\text { for me. }\end{array}$ \\
\hline & 2 & $\begin{array}{l}\text { My chances of getting COVID-19 will be reduced if I get } \\
\text { vaccinated against COVID-19. }\end{array}$ \\
\hline & 3 & $\begin{array}{l}\text { I will be less likely to get COVID-19 if I get vaccinated } \\
\text { against COVID-19. }\end{array}$ \\
\hline \multirow[t]{4}{*}{ Perceived Ability } & & (adapted from Witte et al, 1996) \\
\hline & 1 & I will be able to get vaccinated against COVID-19. \\
\hline & 2 & I am certain that I can get vaccinated against COVID- 19. \\
\hline & 3 & I am confident that I can get vaccinated against COVID-19. \\
\hline \multirow[t]{4}{*}{$\begin{array}{l}\text { Perceived Behavioral } \\
\text { Control }\end{array}$} & & (adapted from Fishbein \& Azjen, 2010) \\
\hline & 1 & Getting a COVID-19 vaccine will be... Up to me. \\
\hline & 2 & Easy for me to do. \\
\hline & 3 & Under my control. \\
\hline \multicolumn{3}{|l|}{ Threat Perceptions } \\
\hline \multirow[t]{4}{*}{$\begin{array}{l}\text { Perceived COVID-19 } \\
\text { Severity }\end{array}$} & & (adapted from Witte et al, 1996) \\
\hline & 1 & COVID-19 has severe consequences. \\
\hline & 2 & COVID-19 is harmful. \\
\hline & 3 & COVID-19 is a serious disease \\
\hline \multirow[t]{4}{*}{$\begin{array}{l}\text { Perceived COVID-19 } \\
\text { Susceptibility }\end{array}$} & & (adapted from Witte et al, 1996) \\
\hline & 1 & I am likely to get COVID- 19. \\
\hline & 2 & My chances of getting COVID-19 are high. \\
\hline & 3 & It is possible that I will get COVID-19. \\
\hline \multirow[t]{9}{*}{ Negative Affect } & & (adapted from Witte et al, 1996) \\
\hline & 1 & When I think about getting COVID-19, I feel... Worried. \\
\hline & 2 & Anxious. \\
\hline & 3 & Nervous. \\
\hline & 4 & Concerned. \\
\hline & 5 & Terrified. \\
\hline & 6 & Scared. \\
\hline & 7 & Fearful. \\
\hline & 8 & Frightened. \\
\hline
\end{tabular}


Table 2 Continued

\begin{tabular}{|c|c|c|}
\hline Information Avoidance & & (adapted from Howell \& Shepperd, 2016) \\
\hline & $\begin{array}{l}2 \\
3 \\
4\end{array}$ & $\begin{array}{l}\text { I would rather not know information about COVID- } 19 \text {. } \\
\text { When it comes to COVID-19 vaccination, sometimes } \\
\text { ignorance is bliss. } \\
\text { When it comes to COVID-19 vaccination, I would be more } \\
\text { comfortable to just turn a blind eye to the issue. } \\
\text { When it comes to COVID-19 vaccination, I would rather not } \\
\text { know the details. }\end{array}$ \\
\hline \multirow[t]{3}{*}{ Information Seeking } & & (adapted from adapted from Fishbein \& Azjen, 2010) \\
\hline & 2 & $\begin{array}{l}\text { I intend to look for more information about COVID-19 } \\
\text { vaccination. } \\
\text { I am motivated to look for more information about COVID-19 } \\
\text { vaccination. } \\
\text { I plan to look for more information about COVID-19 } \\
\text { vaccination. }\end{array}$ \\
\hline & 4 & $\begin{array}{l}\text { I am willing to look for more information about COVID-19 } \\
\text { vaccination. }\end{array}$ \\
\hline Uncertainty Discrepancy & & (adapted from Crowley et al., 2020) \\
\hline \multicolumn{3}{|l|}{ Severity Discrepancy } \\
\hline & 2 & $\begin{array}{l}\text { How much do you know about the negative outcomes of } \\
\text { COVID-19? } \\
\text { How much do you want to know about the negative outcomes } \\
\text { of COVID-19? }\end{array}$ \\
\hline \multicolumn{3}{|l|}{ Susceptibility Discrepancy } \\
\hline & 2 & $\begin{array}{l}\text { How much do you know about your likelihood of getting } \\
\text { COVID-19? } \\
\text { How much do you want to know about your likelihood of } \\
\text { getting COVID-19? }\end{array}$ \\
\hline \multicolumn{3}{|l|}{ Effectiveness Discrepancy } \\
\hline & 1 & $\begin{array}{l}\text { How much do you know about the effectiveness of COVID-19 } \\
\text { vaccines? } \\
\text { How much do you want to know about the effectiveness of } \\
\text { COVID-19 vaccines? }\end{array}$ \\
\hline \multicolumn{3}{|l|}{ Ability Discrepancy } \\
\hline & 2 & $\begin{array}{l}\text { How much do you know about your ability to get vaccinated? } \\
\text { How much do you want to know about your ability to get } \\
\text { vaccinated? }\end{array}$ \\
\hline
\end{tabular}




\section{COVID-19 Vaccine Intentions}

COVID-19 vaccination intention (adapted from Bestch et al., 2018; $\alpha=.79$ ) was measured with five items asking nurses their plans to get vaccinated (e.g., "I intend to get vaccinated against the virus that causes COVID-19.”).

\section{COVID-19 Attitude}

COVID-19 vaccination attitudes were measured on two dimensions: instrumental and affective (adapted from Fishbein \& Azjen, 2010), each using 7-point semantic differential items. Affective attitudes were measured with 4 items $(\alpha=.50)$ indicating general valence towards vaccination (e.g., 1=Bad, 7=Good). Instrumental attitudes were measured with 4 items $(\alpha=.54)$ indicating the general safety and usefulness of vaccination (e.g., 1=Harmful, 7=Beneficial).

\section{COVID-19 Vaccination Social Norms}

Social norms were measured on three dimensions: descriptive, subjective, and injunctive (adapted from Park \& Smith, 2008). Descriptive norms $(\alpha=.70)$ were measured with 3 items (e.g., Most people who are important to me plan on getting vaccinated against COVID-19). Injunctive norms $(\alpha=.67)$ were measured with 3 items (e.g., Most people whose opinions I value would approve of me getting vaccinated). Subjective norms $(\alpha=.73)$ were measured with 3 items (e.g., It is expected of me that I get vaccinated against COVID-19).

\section{COVID-19 Vaccine Efficacy Beliefs}

Efficacy perceptions around COVID-19 vaccines were measured on three dimensions: self-efficacy, perceived behavioral control, and response efficacy. Self-efficacy (adapted from Witte, Cameron, McKeon, \& Berkowitz, 1996; $\alpha=.69$ ) were measured with 3 items (e.g., I will be able to get vaccinated against COVID-19). Perceived behavioral control (adapted from Fishbein \& Azjen, 2010; $\alpha=.71$ ) was measured with 3 items (e.g., Getting a COVID-19 vaccine 
will be up to me). Response efficacy (adapted from Witte et al., 1996; $\alpha=.70$ ) was measured with 3 items (e.g., COVID-19 vaccination is effective in preventing COVID-19 for me).

\section{COVID-19 Threat Perceptions}

COVID-19 threat perceptions were measured on two dimensions: perceived severity and perceived susceptibility (adapted from Witte et al., 1996). Perceived severity ( $\alpha=.79)$ was measured with 3 items (e.g., COVID-19 has severe consequences). Perceived susceptibility $(\alpha=.79)$ was measured with 3 items (e.g., I am likely to get COVID-19).

\section{Negative Affect Towards COVID-19}

Negative affect (adapted from Witte et al., 1996; $\alpha=.79$ ) towards COVID-19 was measured with 8 items (e.g., When I think about getting COVID-19, I feel worried).

\section{Identity}

Identity (adapted from Swann 2009) was measured with a 1 item scale asking to report how they viewed themselves in reference to the title of nurse. For more information see Figure 1.

\section{Figure 1}

Identity Fusion Scale as presented to participants (adapted from Swann, 2009).

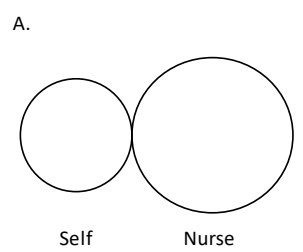

D.
B.

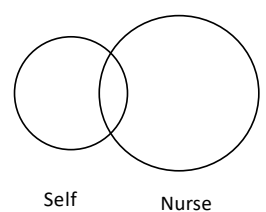

C.

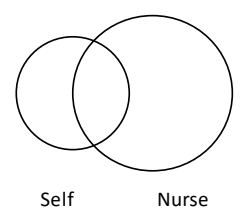

E.

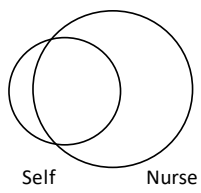




\section{Information Behavior}

Information avoidance (adapted from Howell \& Shepperd, 2016; $\alpha=.87$ ) was measured with 4 items (e.g., I would rather not know information about COVID-19 vaccination).

Information seeking (adapted from Howell \& Shepperd, 2016; $\alpha=.74$ ) was measured with 4 items (e.g., I intend to look for more information).

\section{Perceptions of Uncertainty Discrepancy}

Nurses' uncertainty discrepancy was measured in terms of COVID-19 threat and vaccine efficacy. For each case, items asked nurses how much they knew versus wanted to know about COVID-19's severity, their personal susceptibility to COVID-19, the effectiveness of COVID-19 vaccination, and their own ability to get vaccinated (1=Very little information, $7=\mathrm{A}$ lot of information) (adapted from Crowley et al., 2020). For each measure of uncertainty discrepancy, the rating of how much one knew was subtracted from the level information desired to create an index where positive values indicated a desire for more information and negative values indicated a desire for less information than was known. See Table 1 for specific item wording. 


\section{CHAPTER THREE}

\section{Results}

All analyses were conducted in SPSS. In-text reported coefficients are reported as standardized, when available. Table 3 shows the means, standard deviations, 95\% confidence intervals and correlations for all study variables. 


\section{Table 3.}

Means, standard deviations, and inter-variable correlations for all study variables

\begin{tabular}{|c|c|c|c|c|c|c|c|c|c|c|c|c|c|c|c|c|c|c|}
\hline & $\mathrm{M}(\mathrm{SD})[95 \% \mathrm{CI}]$ & 1. & 2. & 3. & 4. & 5. & 6. & 7. & 8. & 9. & 10. & 11. & 12. & 13. & 14. & 15. & 16. & 17. \\
\hline 1. Vaccination Intention & $5.08(1.17)[4.91,5.24]$ & & & & & & & & & & & & & & & & & \\
\hline 2. Information Seeking Intention & $5.05(1.02)[4.88,5.19]$ & .36 & & & & & & & & & & & & & & & & \\
\hline 3. Information Avoidance & $4.17(1.41)[3.97,4.38]$ & .57 & .14 & & & & & & & & & & & & & & & \\
\hline 4. Perceived Severity & $5.41(1.24)[5.22,5.58]$ & .30 & .61 & .03 & & & & & & & & & & & & & & \\
\hline 5. Perceived Susceptibility & $4.99(1.31)[4.77,5.17]$ & .23 & .48 & .22 & .41 & & & & & & & & & & & & & \\
\hline 6. Negative Affect & $5.13(.88)[5.00,5.25]$ & .51 & .51 & .24 & .61 & .40 & & & & & & & & & & & & \\
\hline 7. Perceived Behavioral Control & $4.56(1.33)[4.37,4.76]$ & .15 & .41 & .28 & .30 & .30 & .29 & & & & & & & & & & & \\
\hline 8. Self-Efficacy & $4.90(1.18)[4.72,5.08]$ & .28 & .60 & .16 & .52 & .32 & .51 & .61 & & & & & & & & & & \\
\hline 9. Response Efficacy & $4.97(1.20)[4.79,5.15]$ & .74 & .30 & .48 & .18 & .10 & .43 & .21 & .34 & & & & & & & & & \\
\hline 10. Descriptive Norms & $4.88(1.13)[4.71,5.04]$ & .78 & .40 & .50 & .28 & .28 & .53 & .14 & .33 & .75 & & & & & & & & \\
\hline 11. Injunctive Norms & $4.96(1.12)[4.80,5.13]$ & .81 & .48 & .46 & .34 & .24 & .51 & .13 & .35 & .81 & .83 & & & & & & & \\
\hline 12. Subjective Norms & $5.01(1.21)[4.83,5.19]$ & .80 & .42 & .47 & .33 & .19 & .54 & .17 & .34 & .82 & .75 & .85 & & & & & & \\
\hline 13. Attitude (Instrument) & $4.79(.92)[4.66,4.92]$ & .46 & .45 & .05 & .43 & .18 & .59 & .01 & .34 & .35 & .44 & .50 & .48 & & & & & \\
\hline 14. Attitude (Affective) & $4.88(.85)[4.75,5.00]$ & .31 & .35 & -.01 & .30 & .12 & .47 & .05 & .19 & .27 & .33 & .43 & .41 & .54 & & & & \\
\hline \multicolumn{19}{|l|}{ Uncertainty Discrepancy } \\
\hline 15. Severity & $-.71(1.58)[-.94,-.49]$ & .25 & .27 & .07 & .48 & .35 & .24 & .08 & .15 & .10 & .18 & .21 & .19 & .16 & .12 & & & \\
\hline 16. Susceptibility & $-.38(1.64)[-.64,-.12]$ & .02 & .42 & -.02 & .27 & .25 & -.07 & -.03 & .03 & -.11 & -.03 & .05 & .03 & .10 & .11 & .24 & & \\
\hline 17. Ability & $-.45(1.76)[-.71,-.20]$ & -.19 & .15 & -.10 & .23 & .05 & .10 & .15 & .19 & .12 & .05 & .05 & .05 & .08 & .13 & .08 & .12 & \\
\hline 18. Effectiveness & $-.48(1.67)[-.74,-.23]$ & .03 & .21 & .03 & .38 & .31 & .04 & -.02 & -.03 & -.12 & .03 & .07 & .07 & .11 & .17 & .53 & .41 & .13 \\
\hline
\end{tabular}




\section{Vaccination Hypothesis Testing}

Hypotheses 1-5 state that nurses' vaccination intentions will be positively predicted by affective attitude (H1a), instrumental attitude (H1b), subjective norms (H2a), descriptive norms (H2b), perceived efficacy (H3), perceived severity (H4a), perceived susceptibility (H4b), negative affect $(\mathrm{H} 4 \mathrm{c})$, and response efficacy (H5). These hypotheses were tested simultaneously by regressing intention on each predictor variable, as shown in Table 4. Hypotheses $1 \mathrm{a}$ and $1 \mathrm{~b}$ were not assessed, as the reliability coefficients for both attitude scales were below conventional standards and the scales were not suitable for analyses.

As can be seen in Table 4 Model 1D, only hypotheses $2 \mathrm{a}, 2 \mathrm{~b}$, and $2 \mathrm{c}$ were supported. In these data, nurses' intention to get vaccinated were predicted only by their perception that important others were planning on getting or had gotten vaccinated (i.e., descriptive norms), standardized beta $=.24$, their perception that important others expected them to get vaccinated (i.e., subjective norms), standardized beta $=.26$, and that important others approved of them getting vaccinated (i.e., injunctive norms), standardized beta $=.31$. Table 4 shows a series of linear regressions with each set of variables added progressively, and it can be seen that before social norms are added, response efficacy and negative affect both predict intention. It is also the case that when the uncertainty discrepancy items are added to the model, response efficacy becomes a statistically significant predictor. Overall, this suggests that social norms are the only predictors of intention of the measured variables, while response efficacy may predict in some circumstances. 
Table 4.

Linear regression results predicting nurses' COVID-19 vaccination intention

\begin{tabular}{|c|c|c|c|c|c|c|c|c|c|c|}
\hline \multirow[t]{2}{*}{$\begin{array}{l}\text { DV: Vaccination } \\
\text { Intention } \\
\end{array}$} & \multicolumn{2}{|c|}{ Model 1A } & \multicolumn{2}{|c|}{ Model 1B } & \multicolumn{2}{|c|}{ Model 1C } & \multicolumn{2}{|c|}{ Model 1D } & \multicolumn{2}{|c|}{ Model 1E } \\
\hline & $\underline{\mathrm{B}(\mathrm{SE})}$ & $\underline{\text { Std. B }}$ & $\underline{\mathrm{B} \text { (SE) }}$ & Std. B & B (SE) & Std. B & B (SE) & Std. B & B (SE) & Beta \\
\hline Perceived Severity & $.22 *(.07)$ & .24 & $-.02(.08)$ & -.03 & $.08(.06)$ & .09 & $.01(.05)$ & 0.01 & $.05(.06)$ & $\overline{0.05}$ \\
\hline $\begin{array}{c}\text { Perceived } \\
\text { Susceptibility }\end{array}$ & $.12(.07)$ & .14 & $.03(.06)$ & .04 & $.08(.04)$ & .09 & $.02(.04)$ & 0.03 & $-.01(.04)$ & -.01 \\
\hline Negative Affect & - & - & $.66 *(.11)$ & .51 & $.24 *(.09)$ & .19 & $.08(.08)$ & 0.06 & $.07(.08)$ & .05 \\
\hline $\begin{array}{l}\text { Perceived Behavioral } \\
\text { Control }\end{array}$ & - & - & - & - & $-.03(.05)$ & -.04 & $.04(.05)$ & 0.05 & $.05(.04)$ & .06 \\
\hline Self-Efficacy & - & - & - & - & $-.09(.07)$ & -.09 & $.10(.06)$ & -.10 & $-.07(.05)$ & -.08 \\
\hline Response Efficacy & - & - & - & - & $.65 *(.05)$ & .68 & $.09(.08)$ & 0.09 & $.17 *(.07)$ & .17 \\
\hline Descriptive Norm & - & - & - & - & - & - & $.25 *(.08)$ & 0.24 & $.26 *(.07)$ & .25 \\
\hline Subjective Norm & - & - & - & - & - & - & $.27 *(.10)$ & 0.26 & $.26 *(.08)$ & .27 \\
\hline Injunctive Norm & - & - & - & - & - & - & $.30 *(.08)$ & 0.31 & $.26(.08)$ & .21 \\
\hline \multicolumn{11}{|c|}{ Uncertainty Discrepancy } \\
\hline Severity & - & - & - & - & - & - & - & - & $-.08 *(.03)$ & -.11 \\
\hline Susceptibility & - & - & - & - & - & - & - & - & $-.03(.03)$ & -.05 \\
\hline Ability & - & - & - & - & - & - & - & - & $.17 *(.03)$ & .26 \\
\hline Effectiveness & - & - & - & - & - & - & - & - & $.04(.03)$ & .06 \\
\hline Constant & $3.24(.42)$ & - & $1.61(.47)$ & - & $.30(.36)$ & - & 0.273 & - & $.15(.3)$ & - \\
\hline$F(d f)$ & \multicolumn{2}{|c|}{$9.93 *(2,172)$} & \multicolumn{2}{|c|}{$19.80 *(3,171)$} & \multicolumn{2}{|c|}{$44.53^{*}(6,168)$} & \multicolumn{2}{|c|}{$50.59 *(9,165)$} & \multicolumn{2}{|c|}{$50.92 *(13,161)$} \\
\hline R-squared & \multicolumn{2}{|c|}{.10} & \multicolumn{2}{|c|}{.26} & \multicolumn{2}{|c|}{.61} & \multicolumn{2}{|c|}{.73} & \multicolumn{2}{|c|}{.80} \\
\hline Adj. R-squared & \multicolumn{2}{|c|}{.09} & \multicolumn{2}{|c|}{.25} & \multicolumn{2}{|c|}{.60} & \multicolumn{2}{|c|}{.71} & \multicolumn{2}{|c|}{.79} \\
\hline
\end{tabular}

Note: $*=\mathrm{p}<.05$ 
Hypothesis seven predicts that nurses' vaccination intention will be indirectly negatively predicted by uncertainty towards threat of COVID-19, mediated by COVID-19 threat perceptions (H7a), and nurses' vaccination intention will be indirectly negatively predicted by uncertainty about COVID-19 vaccination efficacy, mediated by COVID-19 vaccination efficacy perceptions (H7b). These hypotheses were tested using the SPSS PROCESS macro (Hayes, 2013) to conduct a simple mediation analysis (PROCESS Model 4) to calculate a completely standardized indirect effect size of threat uncertainty on intention through threat perceptions and efficacy uncertainty through efficacy perceptions. Given the observations in Table 4 of threat and efficacy perceptions not being statistically significant predictors of intention when norms are controlled for, this precludes testing of mediation as there cannot be an indirect effect without a statistically significant direct effect of the mediator. However, mediation tests were run with and without controls to test if this effect is present when norms are not accounted for.

When tested without controls, the uncertainty discrepancy regarding COVID-19's severity had an indirect effect on intention via perceived COVID-19 severity, $b=.08(.03) 95 \%$ CI $[.01, .14]$ but not when all study variables were included as controls, $b=.002(.02) 95 \%$ CI [$.03, .04]$. The same pattern occurred for the uncertainty discrepancy regarding one's susceptibility to COVID-19 via perceived COVID-19 susceptibility, $b=.04(.02) 95 \%$ CI [.01, $.09]$ without controls and $b=-.004(.01)[-.02, .01]$ with controls, as well as for the uncertainty discrepancy for one's ability to get vaccinated via perceived behavioral control over getting vaccinated, $b=.02(.01)[.0004, .05]$ without controls and $b=-.001(.01) 95 \%$ CI [-.01, .01]

\section{Information Behavior Hypothesis Testing}

Hypotheses six and seven predicted that information seeking (H6) and information avoidance $(\mathrm{H} 7)$ would be predicted by affective attitude (H6a and $\mathrm{H7a}$ ), instrumental attitude 
(H6b and H7b), perceived severity (H6c and H7c), perceived susceptibility (H6d and H7d), negative affect (H6e and H7e), self-efficacy (H6f and H7f), perceived behavioral control (H6g and $\mathrm{H7g}$ ), response efficacy (H6h and H7h), i) subjective norms (H6i and H7i), descriptive norms (H6j and $\mathrm{H} 7 \mathrm{j}$ ), and injunctive norms (H6k and H7k). As in the previous analyses, H6a, $\mathrm{H} 6 \mathrm{~b}, \mathrm{H7} \mathrm{a}$, and $\mathrm{H} 7 \mathrm{~b}$ regarding attitudes were not assessed. Both sets of hypotheses were tested simultaneous by regressing either intention to seeking information or information avoidance on the other study variables, shown in Tables 5 and 6, respectively.

Table 5 (Model 2D) shows that intention to seeking COVID-19 vaccination information was positively predicted by perceived COVID-19 severity (supporting H6a), perceived COVID19 susceptibility (supporting H6b), vaccination self-efficacy (supporting H6f), and subjective norms (supporting H6i). This means that nurses were more motivated to search for more information on COVID-19 vaccination when they thought COVID-19 had serious negative consequences and was likely to affect them, when they felt more confident in their ability to get vaccinated, and when they thought important others expected them to get vaccinated. All other hypotheses were unsupported. Then, to test hypothesis $8 \mathrm{c}$ and $8 \mathrm{~d}$, PROCESS Model 4 was used again to assess the indirect effect of uncertainty discrepancies on intention, controlling for all other predictors. The only nonzero indirect effect was for the severity uncertainty discrepancy, such that as nurses felt that they needed more information about COVID-19's severity, they were less likely to plan to seek more information about COVID-19 vaccines, $b=-.06(.02)[-.11,-.02]$, supporting hypothesis $8 \mathrm{c}$ for severity only. 


\section{Table 5.}

Linear regression results predicting nurses' intention to seek information about COVID-19 vaccination.

\begin{tabular}{|c|c|c|c|c|c|c|c|c|c|c|}
\hline \multirow{2}{*}{$\begin{array}{l}\text { DV: Information } \\
\text { Seeking }\end{array}$} & \multicolumn{2}{|c|}{ Model 2A } & \multicolumn{2}{|c|}{ Model 2B } & \multicolumn{2}{|c|}{ Model 2C } & \multicolumn{2}{|c|}{ Model 2D } & \multicolumn{2}{|c|}{ Model 2E } \\
\hline & $\underline{\mathrm{B}(\mathrm{SE})}$ & Std. B & $\underline{\mathrm{B}(\mathrm{SE})}$ & Std. B & $\underline{\mathrm{B}(\mathrm{SE})}$ & Std. B & $\underline{\mathrm{B}(\mathrm{SE})}$ & Std. B & $\underline{\mathrm{B}(\mathrm{SE})}$ & Std. B \\
\hline Perceived Severity & $.41 *(.05)$ & .50 & $.34 *(.06)$ & .42 & $.27 *(.05)$ & .33 & $.22 *(.05)$ & .27 & $.15 *(.06)$ & .19 \\
\hline $\begin{array}{c}\text { Perceived } \\
\text { Susceptibility }\end{array}$ & $.21 *(.04)$ & .28 & $.19 *(.04)$ & .25 & $.17 *(.04)$ & .23 & $.15 *(.04)$ & .20 & $.10 *(.04)$ & .13 \\
\hline Negative Affect & - & - &. $\mathbf{1 7} *(.08)$ & .16 & $.01(.08)$ & .01 & $-.03(.08)$ & -.03 & $.12(.08)$ & .11 \\
\hline $\begin{array}{l}\text { Perceived Behavioral } \\
\text { Control }\end{array}$ & - & - & - & - & $.02(.05)$ & .029 & $.06(.05)$ & .08 & $.08(.04)$ & .11 \\
\hline Self-Efficacy & - & - & - & - & $.25 *(.06)$ & .30 & $.25 *(.06)$ & .29 & $.23 *(.05)$ & .27 \\
\hline Response Efficacy & - & - & - & - & $.09(.05)$ & .11 & $-.16(.08)$ & -.19 & $-.08(.08)$ & -.10 \\
\hline Descriptive Norm & - & - & - & - & - & - & $-.02(.08)$ & -.03 & $0(.07)$ & .003 \\
\hline Subjective Norm & - & - & - & - & - & - & $.33 *(.10)$ & .36 & $.28 *(.09)$ & .32 \\
\hline Injunctive Norm & - & - & - & - & - & - & $.05(.09)$ & .07 & $-.01(.08)$ & -.02 \\
\hline \multicolumn{11}{|c|}{ Uncertainty Discrepancy } \\
\hline Severity & - & - & - & - & - & - & - & - & $.04(.03)$ & .06 \\
\hline Susceptibility & - & - & - & - & - & - & - & - & $-.21 *(.03)$ & -.34 \\
\hline Ability & - & - & - & - & - & - & - & - & $0(.02)$ & .01 \\
\hline Effectiveness & - & - & - & - & - & - & - & - & $.01(.03)$ & .03 \\
\hline Constant & $1.74(.29)$ & - & $1.31(.35)$ & - & $.80(.35)$ & - & $.74(.33)$ & - & $.65(.34)$ & - \\
\hline $\mathrm{F}(\mathrm{df})$ & \multicolumn{2}{|c|}{$67.25 *(2,172)$} & \multicolumn{2}{|c|}{$47.26 *(3,171)$} & \multicolumn{2}{|c|}{$33.08 *(6,168)$} & \multicolumn{2}{|c|}{$25.70 *(9,165)$} & \multicolumn{2}{|c|}{$25.14 *(13,161)$} \\
\hline R-squared & \multicolumn{2}{|c|}{.44} & \multicolumn{2}{|c|}{.45} & \multicolumn{2}{|c|}{.54} & \multicolumn{2}{|c|}{.58} & \multicolumn{2}{|c|}{.67} \\
\hline Adj. R-squared & \multicolumn{2}{|c|}{.43} & \multicolumn{2}{|c|}{.44} & \multicolumn{2}{|c|}{.53} & \multicolumn{2}{|c|}{.56} & \multicolumn{2}{|c|}{.64} \\
\hline
\end{tabular}

Note: ${ }^{*}=\mathrm{p}<.05$ 
Table 6 (Model 3D) then shows that nurses' avoidance of COVID-19 vaccine information was predicted by perceived severity (but negatively, so H7c was unsupported), perceived behavioral control (supporting $\mathrm{H} 7 \mathrm{~g}$ ), and descriptive norms (supporting $\mathrm{H} 7 \mathrm{j}$ ). This translates into nurses being more likely to avoid COVID-19 vaccine information when they believed other people were planning to get vaccinated and when they believed themselves to be in control of their vaccination decision, but were less likely to avoid information as they thought COVID-19 had more severe consequences. All other hypothesis for direct effects on information avoidance were not supported. Then, to test hypothesis 8e and 8f, PROCESS Model 4 was used again to assess the indirect effect of uncertainty discrepancies on information avoidance, controlling for all other predictors. The only nonzero indirect effect was again for the severity uncertainty discrepancy, meaning that as nurses' need for information on the seriousness of COVID-19 increased, the more serious they thought COVID-19 was, and because of that, they more strongly avoided COVID-19 vaccine information, $b=.07(.02)[-.11,-.02]$. 
Table 6.

Linear regression results predicting nurses' avoidance of information about COVID-19 vaccination.

\begin{tabular}{|c|c|c|c|c|c|c|c|c|c|c|}
\hline \multirow{2}{*}{$\begin{array}{l}\text { DV: Information } \\
\text { Seeking }\end{array}$} & \multicolumn{2}{|c|}{ Model 3A } & \multicolumn{2}{|c|}{ Model 3B } & \multicolumn{2}{|c|}{ Model 3C } & \multicolumn{2}{|c|}{ Model 3D } & \multicolumn{2}{|c|}{ Model 3E } \\
\hline & $\underline{\mathrm{B}(\mathrm{SE})}$ & $\underline{\text { Std. B }}$ & $\underline{\mathrm{B}(\mathrm{SE})}$ & $\underline{\text { Std. B }}$ & $\underline{\mathrm{B}}(\mathrm{SE})$ & $\underline{\text { Std. B }}$ & $\underline{B}(\mathrm{SE})$ & $\underline{\text { Std. B }}$ & $\underline{\mathrm{B}(\mathrm{SE})}$ & Std. B \\
\hline Perceived Severity & $-.08(.09)$ & -.076 & $-.27(.1)$ & -.24 & $-.20(.09)$ & -.18 & $-.23 *(.09)$ & -.20 & $-.25 *(.11)$ & -.22 \\
\hline $\begin{array}{c}\text { Perceived } \\
\text { Susceptibility }\end{array}$ & $.26 *(.08)$ & .25 & $.20 *(.08)$ & .19 & $.19 *(.07)$ & .18 & $.13(.07)$ & .13 & $.09(.08)$ & .09 \\
\hline Negative Affect & - & - & $.49(.14)$ & .31 & $.13(.14)$ & .09 & $-.01(.14)$ & -.01 & $.05(.15)$ & .03 \\
\hline $\begin{array}{c}\text { Perceived Behavioral } \\
\text { Control }\end{array}$ & - & - & - & - & $.26 *(.08)$ & .25 & $.32 *(.08)$ & .31 & $.33 *(.08)$ & .31 \\
\hline Self-Efficacy & - & - & - & - & $-.18(.11)$ & -.16 & $-.19(.10)$ & -.16 & $-.15(.11)$ & -.13 \\
\hline Response Efficacy & - & - & - & - & $.53 *(.08)$ & .46 & $.12(.14)$ & .11 & $.24(.15)$ & .21 \\
\hline Descriptive Norm & - & - & - & - & - & - & $.35 *(.14)$ & .29 & $.35 *(.14)$ & .29 \\
\hline Subjective Norm & - & - & - & - & - & - & $.06(.18)$ & .05 & $.01(.18)$ & .01 \\
\hline Injunctive Norm & - & - & - & - & - & - & $.19(.15)$ & .17 & $.11(.16)$ & .10 \\
\hline \multicolumn{11}{|c|}{ Uncertainty Discrepancy } \\
\hline Severity & - & - & - & - & - & - & - & - & $.01(.07)$ & .02 \\
\hline Susceptibility & - & - & - & - & - & - & - & - & $-.02(.06)$ & -.03 \\
\hline Ability & - & - & - & - & - & - & - & - & $.11 *(.05)$ & .14 \\
\hline Effectiveness & - & - & - & - & - & - & - & - & $-.09(.07)$ & -.12 \\
\hline Constant & $3.3(.52)$ & - & $2.1(.62)$ & - & $.61(.59)$ & - & $.59(.57)$ & - & $.42(.64)$ & - \\
\hline$F(d f)$ & \multicolumn{2}{|c|}{ 4.71* $(2,172)$} & \multicolumn{2}{|c|}{$\mathbf{7 . 0 0} *(3,171)$} & \multicolumn{2}{|c|}{$13.26 *(6,168)$} & \multicolumn{2}{|c|}{$\mathbf{1 . 9 4} *(9,165)$} & \multicolumn{2}{|c|}{ 8.16* $(13,161)$} \\
\hline R-squared & \multicolumn{2}{|c|}{.05} & \multicolumn{2}{|c|}{.11} & \multicolumn{2}{|c|}{.32} & \multicolumn{2}{|c|}{.37} & \multicolumn{2}{|c|}{40} \\
\hline Adj. R-squared & \multicolumn{2}{|c|}{.04} & \multicolumn{2}{|c|}{.09} & \multicolumn{2}{|c|}{.30} & \multicolumn{2}{|l|}{.34} & \multicolumn{2}{|c|}{.35} \\
\hline
\end{tabular}

Note: $*=\mathrm{p}<.05$ 


\section{Research Question}

The research question asked how the extent to which nurses view nursing as a part of their identity affected their vaccine decision-making. This was assessed in two ways: first by using identity as a moderator for the indirect effects of uncertainty discrepancy on the three outcome variables, and then as a moderator of the individual predictors' direct effects.

PROCESS Model 14 was used to test whether nursing identity moderated the indirect effects of each type of uncertainty discrepancy on each outcome. The only significant moderated mediation for vaccination intention was in the case of severity uncertainty discrepancy, index of moderated mediation $=-.04(.02)[-.09,-.02]$, in that at the highest degree of identity (E in Figure 1), the need for information regarding COVID-19's severity had a negative indirect effect on vaccination intention, $b=-.04(.03)[-.10,-.0001]$, but did not have an indirect effect at lower degrees of nurse identification. The severity information need indirect effect was also significantly moderated for intention to seek information, index of moderated mediation $=-.05$ (.02) $[-.09,-.01]$, in that the indirect effect was only present for nurses in the two highest order identity groups, $b=-.06(.03)[-.11,-.01]$ for $\mathrm{D}$ in Figure 1 and $b=-.11(.04)[-.18,-.04]$ for $\mathrm{E}$ in Figure 1. There was no evidence of moderated mediation for any of the indirect effects on information avoidance.

PROCESS Model 1 was used to test whether nursing identity moderated each predictor variable on all three outcomes. What emerged (shown in Table 7) is that those nurses who entirely defined themselves as nurses, descriptive norms were no longer a significant predictor of vaccination intention, but intention was positively predicted by perceived severity, $b=.21(.08)$ $[.05, .26]$, perceived susceptibility, $b=.10(.05)[0, .21]$, and perceived behavioral control, $b=.15$ 
$(.06)[.04, .26]$. For nurses who only partially identified with the social group of nurses, intention was predicted by the same variables, but with some notable differences.

Table 7.

Moderation of direct effects of vaccination intention and information seeking, by level of nurse identity.

$\underline{\text { Moderator Levels (Level of Nurse Identity Selected) }}$
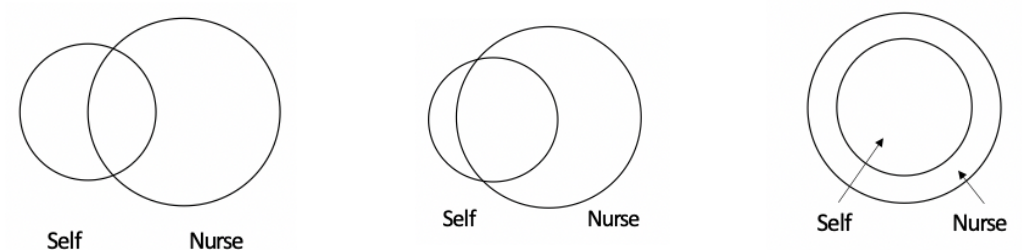

Intention to Vaccinate

Perceived Severity

Self

Nurse

$$
\begin{array}{lll}
-.15(.07)[-.28,-.01] & .03(.05)[-.07, .13] & .21(.08)[.05, .36] \\
-.13(.07)[-.26,-.01] & -.02(.04)[-.10, .07] & .10(.05)[0, .21] \\
& \text { No Moderation } & \\
& \text { No Moderation } &
\end{array}
$$

Negative Affect

Self-Efficacy

Perceived Behavioral Control

$$
-.18(.07)[-.33,-.04] \quad-.02(.05)[-.11, .08] \quad .15(.06)[.04, .26]
$$

Response Efficacy

No Moderation

Descriptive Norm

$.321(.08)[.16, . .49]$

Subjective Norm

.24 (.08) [.07, .40]

$.15(.10)[-.06, .36]$

Injunctive Norm

No Moderation

No Moderation

\section{Information Seeking Intention}

Perceived Severity

Perceived Susceptibility

Negative Affect

Self-Efficacy

Perceived Behavioral Control

Response Efficacy

Descriptive Norm

Subjective Norm

Injunctive Norm
$.05(.07)[-.09, .19]$

$$
-.03(.08)[-.19, .13]
$$$$
.26(.07)[.13, .39]
$$

$.23(.05)[.13, .34]$

$.41(.08)[.25, .57]$ No Moderation

$.17(.09)[-.003, .34]$

$.36(.11)[.14, .59]$

$.37(.06)[.24, .50]$

$.48(.09)[.31, .65]$

No Moderation

No Moderation

$$
\begin{array}{ccc}
-.04(.08)[-.20, .12] & .15(.08)[-.02, .31] & .34(.10)[.13, .54] \\
.04(.09)[-.13, .21] & .15(.09)[-.02, .32] & .26(.10)[.06, .46] \\
-.04(.12)[-.29, .20] & .15(.10)[-.05, .36] & .35(.11)[.14, .57]
\end{array}
$$


While descriptive norms were positive predictors for this set of nurses, $b=.32(.08)[.16$, .49 ], intention was now negatively predicted by perceived severity, $b=-.15(.07)[-.28,=.01]$, perceived susceptibility, $b=-.13(.07)[-.26,-.01]$, and perceived behavioral control, $b=-.18$ (.07) $[-.33,-.04]$. For those who only partially identified as a nurse, seeing COVID-19 as increasingly serious was associated with lower intention to get vaccinated, seeing oneself as more likely to get COVID-19 was associated lower intention to vaccinate, and greater perceived control over vaccination was associated with lower intention to get vaccinated. In other words, seeing COVID-19 as a threat decreased motivation to vaccinate, as did feeling in control. While these factors diminish motivation, believing that others were going to get vaccinated was associated with greater intention to get vaccinated oneself.

For nurses' intention to seek COVID-19 vaccine information, identity moderated several variables' effects. For nurses with the lowest observed identification level, seeking intention was only predicted by perceived ability and perceived susceptibility. This means that for these nurses, perceiving greater control over vaccination and greater likelihood of getting COVID-19 lead to more motivation to search for information on COVID-19 vaccines. For nurses at the highest level of identification, the same pattern as the primary analyses (Table 4) was observed. No moderation in predicting information avoidance was observed. 


\section{CHAPTER FOUR}

\section{Discussion}

The COVID-19 pandemic has cost the world many and the end remains undefined. The most direct path to ending the pandemic is through vaccination and reaching herd immunity (WHO, 2021). As previously stated, nurses have been shown to be more hesitant towards the COVID-19 vaccines as uptake rates for nurses are low (e.g., Dror et al., 2021). It is vital to understand how nurses are making their COVID-19 vaccination decision because they are a trusted information source to the community that surrounds them and to the patients that they treat (Clayton \& Ellington, 2011; Silk et al., 2019). Observing vaccination decision making through the broad lens of uncertainty is a novel approach to the ways these decisions are made specifically within the identity group of nurses. Through using the 5c Model, Integrative Model, Extended Parallel Process Model, Uncertainty Management, and The Motivated Information Management Model in collaboration, this thesis explores the nature of nurses' vaccination decision making to gain understanding and provide potential suggestions on how to overcome low uptake rates.

The framework within this thesis was derived from the $5 \mathrm{C}$ model, the model is oriented towards health behavior and uses concepts that revolve around vaccination intention such as confidence, constraints, complacency, calculation, and collective responsibility. While this model is representative of vaccination intention, it lacks a social scientific perspective. To build on the 5C model, the Integrative Model as well as the EPPM were included to further understand decision making through a Communication Science lens. The Integrative Model closely aligns with several concepts from the 5C model such as attitude and confidence, perceived norms and collective responsibility, and perceived efficacy and constraints. While the EPPM closely aligns 
with concepts from the $5 \mathrm{c}$ model as well; perceived threat resembles complacency while response efficacy resembles both attitude from the Integrative Model and confidence from the 5C model. Although these models are not typically used in unison, this approach allowed for a more focused analysis of decision making as it relates to the COVID-19 vaccination decision among nurses. Additionally, this framework sought to expand the evaluation of vaccination intention through the individual aspects of decision making to gain deeper understanding of the influences among decision making. To summarize, the thesis set out to gain understanding of the nature of nurse's COVID-19 vaccination decision through a unique framework within an applied setting.

The population within this thesis consisted of nurses within a single state, West Virginia, so when generalizing there may be state specific considerations to include such as availability of vaccine and accessibility to vaccination. Specific to this population, the nurses were young, with an average age of 34.85 years which could provide a partial explanation for the importance of norms described in the findings below. As nurses build their career, they may become more in tune with what it means to be a nurse because of the social guidance that is derived from the nurses around them. The social group that surrounds the individual is seen as important and likely more so as the time spent within that social group increases.

The main findings of this thesis were that West Virginia nurses' intentions to get vaccinated against the virus that causes COVID-19 were only predicted by normative pressure to get vaccinated. This is contrary to on-going research in West Virginia that suggest the general public are motivated by a mix of the same factors measured in this thesis, and prevailing theory in Communication Studies that would suggest all variables would predict behavioral intention generally. It was also the case that, when social norms were accounted for, the expectation that 
need for information (i.e., uncertainty discrepancy) specific to each aspect of threat and efficacy would exert an indirect effect on motivation was not supported. However, this expectation was observed in the case of need for COVID-19 severity information and for those nurses who moderately identified personally as a nurse and not those with the most extreme nursing identification. These same nurses were more likely to get vaccinated if it appeared that other people important to them plan to get vaccinated and support or expect their getting vaccinated but were less likely to do so as their perception of the threat of COVID-19 increased. Social norms remained strong predictors of intention to vaccinate, but largely did not predict information seeking. Meanwhile, nurses fully identifying as nurses exhibited largely what would be expected from behavioral theories, being specifically motivated by risk perceptions and efficacy beliefs, and the belief that other people expected them to get vaccinated. These nurses were also motivated to search for more information by both threat perceptions and social norms.

\section{Uncertainty in Vaccination Decision-Making}

The main goal of this thesis was to examine how uncertainty and the need for information play into vaccine decision-making. Findings largely suggested that uncertainty did not affect vaccine decision-making, but it appears that this was mostly a product of how social norms having an outsized role in this decision-making process. When more closely examining the results, it does appear that uncertainty surrounding the risk posed by the virus that causes COVID-19 specifically may influence decision making. Nurses who had a "fully fused" identity were affected in part by a need for additional information about how serious COVID-19 is as a risk. For these nurses, feeling like there was more to know about the risk of COVID-19 reduced the likelihood that they planned to get vaccinated. For nurses within this identity subgroup, the risk surrounding COVID-19 was unclear, and therefore the health threat remained unclear and 
confused motivation to get vaccinated. Needing more information about a health threat may encourage a person to hold off on the risk-reducing behavior because they do not see the benefit of it. Without perceiving something as a risk, there is not a need to act in a protective or preventative manner, and using the lens of uncertainty helps to better define what it means to assess risk.

It has been previously observed that uncertainty associated with a solution may influence individuals to act in defensive avoidance and thus controlling their fear without having to take protective action (Goodall \& Reed, 2013), otherwise known as "fear control" in the EPPM (Popova, 2012). This was not directly observed in this thesis due to not having enough statistical power to test an additional moderator of efficacy and its uncertainty, but some findings tangentially speak to this. As will be discussed below, this thesis suggests that some nurses are using cues from their social groups to guide their decisions, rather than risk-related information. By relying on identity groups for information, it is likely that individuals have reduced uncertainty around what they should do, as they are given direction directly and indirectly from others' behavior, and thus follow the guidance of that group as a means of defensive avoidance or fear control. Defensive avoidance can result in the reliance on heuristics or cognitive shortcuts over more deliberative judgements (Chaiken \& Ledgerwood, 2012), and the data here might show the outcome of such avoidance. Results also suggest that the nurses in this sample may have a high tolerance for uncertainty, as the uncertainty around the threat and efficacy were not significant indicators of vaccination intention. People with high tolerance for uncertainty are likely not influenced by uncertainty that surrounds threat and efficacy (Goodall \& Reed, 2013). However, while the main findings showed no effect of risk on intentions, the moderation findings show that this is actually due to the positive influence of risk perceptions for nurses with 
fully fused identity (i.e., a danger control process) getting cancelled out by the negative influence of risk perceptions for nurses with less fused identities (i.e., a fear control process or a boomerang effect; Popova, 2012).

The conceptualization of this thesis was unique in the models and theories used to create the perspective the study utilized. Vaccination decision-making studies have not previously been observed through a macro lens of uncertainty that surrounds a virus and information about it, but focus more closely on the vaccine itself or uncertainty in general. One important point of this thesis is the kind of uncertainty that is being observed surrounds the ambiguity and information derived from the virus itself and how that affects how people view the vaccines. More detailed information about how people make decisions around risks and risk-reducing behaviors can be observed by breaking down uncertainty and need for information in these more specific ways.

\section{Identity, Social Norms, and Vaccination Decision-Making}

Although this thesis was not specifically focused on the social performance of the nursing identity, it does provide evidence that there is social influence when belonging to that group. A number of dynamics were observed in nurses' decision-making around COVID-19 vaccination based on normative pressures and different extents of identity fusion. Social norms were at times the only predictors of vaccination intention and were specifically important for nurses who viewed themselves as having a half-fused identity: they viewed being a nurse as only part of their overall identity. These nurses' decision making was driven primarily by the cues they took from others which did not lead to additional searching for information, while the behavior of those nurses with fully-fused identities were not as strongly driven by social pressures.

Through the lens of Social Identity Theory, motivation is oriented to benefit the collective (Willets \& Clark, 2014). In other words, membership to an identity group requires 
motivation to act on behalf of the group. For those individuals that are not entirely fused with that specific identity, they may be inclined to act on behalf of the group for membership verification (Swann et. al., 2009). Social norms or social pressure act as a guide for those members more on the outskirts of group membership to provide evidence that they support the group to which they belong. In other words, when people feel only partially connected to a group, they may enact behaviors that can "confirm" they belong to that group and thus overcome insecurity that may be associated with not fully being part of that group. The nature of the decision to get the COVID-19 vaccination is a personal and intimate decision, so it can be useful to reference important others who are close in identity or representative of an identity group one aligns with.

Group salience, or how top-of-mind a group identity is, is contextual (Willets \& Clark, 2014), meaning that an identity will be viewed as more important when the need for that identity is more prominent. For nurses during a pandemic, it could be assumed that the nursing identity has taken a special priority or precedent within their lives, possibly more than it would normally. In this specific context the group membership or identity could have become more salient creating a stronger motivation to act on behalf of the group. By standing together, the group norms are oriented towards a goal, or group motivated behavior.

When applying these findings to the general public, it should be noted that the people they affiliate with may influence their vaccination decision most. Providing the public with information and encouraging them to get vaccinated may not do an adequate job of raising uptake rates. When a person is fused or a complete member of their identity group then they may use behavior as a way to verify their standing socially within that group (Swann et al., 2009). By not getting vaccinated nurses are banning together and verifying the salience of their group 
membership. As seen within this thesis, nurses were most influenced by the social norms within their identity group, and not necessarily the risk that they perceive the virus to pose. To break through the social barrier, vaccination campaigns should consider infiltrating the normative pressures that different identity groups may face.

\section{Theoretical Implication}

This thesis began with the 5C Model (Bestch et al., 2018), a vaccination intention model that related closely to several theories within Communication Studies such as the Integrative Model (Yzer, 2012) and the EPPM (Basil \& Witte, 2012). Adding the concept and observation of uncertainty provided an opportunity to understand where and how people are making decisions when there is little certainty in the information available surrounding the decision. Through collaborating these theories as the base framework health and communication have become closer through research which expands the practical framework of the 5C Model. With using communication theories alongside the 5C Model this thesis was able to observe the social role of vaccination decision making. However, what was captured in this thesis provides some evidence that there needs to be more research within applied settings to test what these theories pose and attempt to measure. Notably, many research populations consist of students, and students are particularly familiar with taking surveys as well as participating within research due to the nature of university communities and department research goals. Thus, theoretical assumptions and additions are derived from a population that may not be the true target audience of observation, but a narrow subset of who may be affected. Then when applied in a specific context the rules do not necessarily always carry over. By applying multiple theories within an applied setting it creates a more holistic approach to view the social phenomenon that this research wishes to capture. 


\section{Recommendations for COVID-19 Vaccination Messaging}

As an extension of on-going formative research to inform statewide COVID-19 vaccination messaging, it is important to consider how these results could be translated into occupation-specific message to promote COVID-19 vaccination among nurses. Based on the results discussed above, one recommendation would be to target the norms within the nursing identity group, create the idea that getting vaccinated against COVID-19 is a normative behavior; showcase that nurses specifically are getting vaccinated and doing so is part of what makes one a nurse. Framing the decision in this way may encourage the interpretation of vaccination being closely aligned with the values of the nursing identity group. Another recommendation is to target the values and beliefs of that identity group specifically. Nurses are known to be tough and resilient because the profession requires it and they are trained for it, to make the vaccine something that will provide stamina to their resilience could provide an opening for a reevaluation of information to potentially begin the process of reconsidering vaccination. The suggested behavior, COVID-19 vaccination, needs to align with the values that are held by the identity group creating a similar interest or goal. The group differences in the role of risk perception also suggest that focusing on the threat posed by COVID-19 might backfire for some nurses, despite it being a benefit in current research with the general public that this thesis is an extension of. Relying on norms is a consistent and positive influence on intention, while severity and susceptibility perceptions might decrease intention for some nurses.

Taking a social marketing approach could also be beneficial to increasing COVID-19 vaccination rates because it would correspond with the values of the target audience (Dearing, 2015). By "selling" the idea of COVID-19 vaccination as something that is an essential part of their identity could help to encourage the consideration of the health behavior. Looking to 
opinion leaders within identity groups to lead by example and get the COVID-19 vaccine would help to support that people important to the group are in agreement with the behavior (Dearing, 2015). People will look to those leaders as trusted sources of information about both the group and behavior, if they approve then the group can approve and adopt the behavior.

\section{Future Directions}

Moving forward, there are several directions that may be beneficial to pursue to better understand the nursing identity and profession. Observing the nursing identity in relation to work roles and time spent with patients could offer insight to how nurses identify, or how fused the nursing identity is to them. Exploring this avenue may also offer some explanation to past research about nurses' behavior as well as there being limited social science research with a nursing population. Furthermore, it could be of interest to expand research to study identity and its' role in decision making in different context as well as professions, or other social groups. As well as using the Identity Fusion Scale within other professional and applied contexts. This could potentially offer insight as to which groups are using norms within decision making, and which social groups give norms a higher precedent when making important decisions. For vaccination decision-making specifically, observing more closely the social influence that may be taking place could extend current knowledge about how to encourage vaccination and potentially other health behaviors. Another suggestion is to use messages targeting norms to observe effectiveness of the health message for nurses. This could help guide health campaigns to encourage vaccination and possibly other health behaviors. Lastly, a closer look into uncertainty and the role that it plays within decision making, specifically the uncertainty discrepancy related to threat and efficacy to better understand what the uncertainty is truly about. This avenue may also 
provide additional understanding of what information people want and need during a crisis situation.

\section{Limitations}

One limitation throughout this thesis was that attitude scales having low reliability, and therefore having to be withheld from analysis. Unfortunately, this resulted in several hypotheses not being tested. As many social science scales are created and used in student samples and not in applied settings, it would be beneficial to construct attitude scales for the applied setting or at a minimum better adapt scales for this kind of use. Within this study, results from the attitude scales could have reflected a normative attitude form the nursing identity group or provided explanatory power as to if different subgroups had different attitudes about COVID-19 and the vaccines. Additionally, this thesis was cross sectional and therefore causal claims could not be made. The sample was a convenience sample, recruited from the WV Nurses Association to complete a COVID-19 survey, so participants were likely particularly interested and thus potentially skewing the results. A larger sample may have provided a fuller spectrum of partially to fully-fused identities and could have potentially given more insight to the influence that social norms play within the identity group of nursing. The conservative sample size also made group comparisons unrealistic because there was not enough statistical power. Lastly, vaccines have been available to nurses some time before this survey was administered, as they were among the first priority to vaccinate, so this may have allowed time for their beliefs to become solidified around COVID-19 and COVD-19 vaccination.

\section{Conclusion}

This thesis sought to further understanding about uncertainty within vaccination decision making. It hoped to address the current vaccination barriers that have resulted in low uptake for 
nurses COVID-19 vaccines. Overall, nurses were more influenced by norms, or social pressure when making the decision to get the COVID-19 vaccine. This thesis sheds light on the social performance of identity on a preventative and protective health behavior. The social constructs of our lives and any decision may be subject to influence by those that surround us, but more research would help to provide a clearer understanding of the degree to which it may occur. 


\section{References}

Afifi, W., \& Weiner, J. L. (2004). Toward a theory of motivated information management. Communication Theory, 14(2), 167-190. https://doi.org/10.1111/j.14682885.2004.tb00310.x

Ajzen, I. (2001). Nature and operation of attitudes. Annual Review of Psychology, 52(1), 27-58. https://doi.org/10.1146/annurev.psych.52.1.27

Ajzen, I. (2002). Perceived behavioral control, self-efficacy, locus of control, and the theory of planned behavior. Journal of Applied Social Psychology, 32(4), 665-683.

Allport, G.W. (1954). The nature of prejudice. New York: Doubleday Books.

Andre, F. E., Booy, R., Bock, H. L., Clemens, J., Datta, S. K., John, T. J., Lee, B. W., Lolekha, S., Peltola, H., Ruff, T. A., Santosham, M., \& Schmitt, H. J. (2008). Vaccination greatly reduces disease, disability, death and inequity worldwide. Bulletin of the World Health Organization, 86(2), 140-146. https://doi.org/10.2471/BLT.07.040089

Basil, M., \& Witte, K. (2012). Health risk message design using the extended parallel process model. Chapter 3. SAGE Publications. 41(58).

Bedford, H., Attwell, K., Danchin, M., Marshal, H. Corebn, P., \& Leask, J. (2017). Vaccine hesitancy, refusal and access barriers: the need for clarity in terminology. Vaccine. http://dx.doi.org/10/1016/j.vaccine.2017.08.004

Berger, C. R., \& Calabrese, R. J. (1975). Some explorations in initial interaction and beyond: Toward a developmental theory of interpersonal communication. Human Communication Research, 1, 99-112. 
Bestch, C., Schmid, P., Heinemeier, D., Korn, L., Holtmann, C., \& Bohm, R. (2018). Beyond confidence: development of a measure assessing the 5C psychological antecedent of vaccination. PLoS ONE, 13(12). https://doi.org/10.1371/journal.pone,0208601

Brashers, D. E. (2001). Communication and uncertainty management. Journal of Communication. 51, 477-497

Brashers, D. E., Neidig, J. L., \& Goldsmith, D. J. (2004). Social support and the management of uncertainty for people living with HIV or AIDS. Health Communication, 16, 305-331.

Caroselli, C. (2020). A journey through uncharted territory: a nurse executive's frontline pandemic response. Nursing Economic\$. 38(3), 164-171.

Case, D. O., Andrews, J. E., Johnson, J. D., \& Allard, S. L. (2005). Avoiding versus seeking: the relationship of information seeking to avoidance, blunting, coping, dissonance, and related concepts. Journal of the Medical Library Association, 93(3), 353-362.

Centers for Disease Control and Prevention. (2021, May 4). COVID-19. https://www.cdc.gov/coronavirus/2019-ncov/index.html

Chaiken, S., \& Ledgerwood, A. (2012). A theory of heuristic and systematic information processing. In P. A. M. Van Lange, A. W. Kruglanski, \& E. T. Higgins (Eds.), Handbook of theories of social psychology (pp. 246-266). Thousand Oaks, CA: SAGE

Chou, W. S., Gaysynsky, A., \& Vanderpool, R. C. (2020). The COVID-19 misinfodemic: Moving beyond fact-checking. Health Education \& Behavior, 48 (1), 9-13. https://doi.org/10.1177/10901980675

Clayton, M. F., \& Ellington, L. (2011). Beyond primary care providers: A discussion of health communication roles and challenges for health care professionals and others. In T. L. 
Thompson, R. Parrott, \& J. F. Nussbaum (Eds.), The Routledge handbook of health communication (2nd ed., pp. 69-83). New York: Routledge.

Crowley, J. P., Bleakley, A., Silk, K., Young, D. G., \& Lambe, J. L. (2021). Uncertainty management and curve flattening behaviors in the wake of COVID-19's first wave. Health Communication, 36 (1), 32-41. DOI:10.1080/10410236.2020.1847452

Dearing, J. W. (2015). Social marketing and the diffusion of innovations. In D. W. Stewart (Ed.), The handbook of persuasion and social marketing (Vol. 2, pp. 35-66). Santa Barbara, CA: Praeger.

del Carmen Aguilar-Díaz, F., Jiménez-Corona, M. E., \& Ponce-de-León-Rosales, S. (2011). Influenza vaccine and healthcare workers. Archives of medical research, 42(8), 652-657. https://doi.org/10.1016/j.arcmed.2011.12.006

Dooling, K. Marin, M., Wallace, M., McClung, N., Chamberland, M., Lee, G. M., Talbot, H. K., Romero, J. R., Bell, B. P., \& Oliver, S. E. (2021). The Advisory Committee on Immunization Practices' updated interim recommendation for allocation of COVID-19 vaccine - United States, December 2021. Morbidity and Mortality Weekly Report, 69(5152), 1657-1660. https://doi.org/10.15585/mmwr.mm695152e2.

Dror, A. A., Eisenbach, N., Taiber, S., Morozov, N. G., Mizrachi, M., Zigron, A., Srouji, S., \& Sela, E. (2020). Vaccine hesitancy: The next challenge in the first against COVID-19. European Journal of Epidemiology, 35, 775-779. https://doi.org/10.1007/s10654-02000671-y

Erzurum, S. (2021, February 04). How much of the population will need to be vaccinated until the pandemic is over? Retrieved February 19, 2021, from 
https://health.clevelandclinic.org/how-much-of-the-population-will-need-to-bevaccinated-until-the-pandemic-is-over/

Fuchs, M. A., Mason, D., \& Marshall-Blake, L. (2021). Nurses on the frontline: Strengthening America's healthcare workforce [Webinar]. NIHCM Foundation. https://nihcm.org/publications/nurses-on-the-frontline-strengthening-americas-healthcare-workforce?utm_source=NIHCM+Foundation\&utm_campaign=d4993329a5EMAIL_CAMPAIGN_2020_12_03_03_17_COPY_01\&utm_medium=email\&utm_term =0_6f88de9846-d4993329a5-167870092

Goodall, C. E., Reed, P. (2013). Threat and efficacy uncertainty in news coverage about bed bugs as unique predictors of information seeking and avoidance: An extension of the EPPM. Health Communication, 28(1), 63-71. https://doi.org/10.1080/10410236.2012.689096

Hayes, A. F. (2013). Introduction to mediation, moderation, and conditional process analysis: A regression-based approach. The Guilford Press.

Helms, J. E., \& Cook, D. A. (1999). Using race and culture in counseling and psychotherapy: Theory and process. Allyn and Bacon.

Howell, J. L., \& Shepperd, J. A. (2016). Establishing an Information Avoidance Scale. Psychological Assessment, 28(12), 1695-1708. https://doi.org/10.1037/pas0000315

Kahlor, L. (2010). PRISM: A planned risk information seeking model. Health Communication, 25(4), 345-356. https://doi.ord/10.1080/10410231003775172 
Lukacena, K. M., Reynolds-Tylus, T., \& Quick, B. L. (2017). An application of the reasoned action approach to bystander intervention for sexual assault. Health Communication. 34(1), 46-53. https://doi.org/10.1080/10410236.2017.1384356

MacDonald, N. E. (2015). Vaccine hesitancy: Definition, scope and determinants. Vaccine, 33(34), 4161-4164. https://doi.org/10.1016/j.vaccine.2015.04.036

Ng, T. W.Y., Cowling, B. J., So, H. C., Ip, D. K. M., \& Liao, Q. (2019). Testing an integrative theory of health behavioral change for predicting seasonal influenza vaccination uptake among healthcare workers. Vaccine. https://doi.org/10.1016/j.vaccine.2019.10.041

Park, H., \& Smith, S. W. (2007). Distinctiveness and influence of subjective norms, personal descriptive and injunctive norms, and societal descriptive and injunctive norms on behavioral intent: A case of two behaviors critical to organ donation. Human Communication Research, 33(2), 194-218. https://doi.org/10/1111/j.1468-2958.00296.x

Popova, L. (2012). The extended parallel process model: Illuminating the gaps in research. Health Education \& Behavior, 39(4), 455-472. https://doi.org/10.1177/1090198111418108

Salazar, C. F., \& Abrams, L. P. (2005). Conceptualizing identity development in members of marginalized groups. Journal of Professional Counseling: Practice, Theory \& Research, 33(1), 47-59. https://doi.org/10.1080/15566382.2005.12033812

Sethi, A., Aamir, H. S., Sethi, B. A., Ghani, N., \& Saboor, S. (2020). Impact of frontline nurses in the fight against coronavirus disease. Annals of King Edward Medical University. 26, $120-125$.

Silk, K. J., Walling, B., Totzkay, D., Mulroy, M., Smith, S. W., Quaderer, T., Boumis, J., \& Thomas, B. D. H. (2019). Continuing medical education as a translational science 
opportunity for health communication researchers: The BCERP model. Health Communication. https://doi.org/10.1080/10410236.2019.1625003

Shaw, J., Stewart, T., Anderson, K. B., Hanley, S., Thomas, S. J., Salmon, D. A., \& Morley, C. (2021). Assessment of U.S. health care personnel (HCP) attitudes towards COVID-19 vaccination in a large university health care system. Clinical Infectious Diseases. https://doi.org/10.1093/cid/ciab054

Shourie, S., Jackson, C., Cheater, F. M., Bekker, H. L., Edlin, R., Tubeuf, S. et al. (2013). A cluster randomized controlled trial of a web-based decision aid to support parents decisions about their child's measles mumps and rubella (MMR) vaccination. Vaccine, 31(50), 60036010.

Swann, W. B., Huici, C., \& Gomez, A. (2009). Identity fusion: the interplay of personal and social identities in extreme group behavior. Journal of Personality and Social Psychology. DOI: 10.1037/a0013668

Taylor, Derrick Bryson. "A Timeline of the Coronavirus Pandemic.” The New York Times, The New York Times, 13 Feb. 2020, www.nytimes.com/article/coronavirus-timeline.html.

Turner, M. M., Rimal, R. N., Morrison, D., \& Kim, H. (2006). The Role of Anxiety in Seeking and Retaining Risk Information: Testing the Risk Perception Attitude Framework in Two Studies. Human Communication Research, 32(2), 130-156. https://doi.org/10.1111/j.1468-2958.2006.00006.x

Willetts, G., \& Clarke, D. (2014). Constructing nurses' professional identity through social identity theory. International Journal of Nursing Practice (John Wiley \& Sons, Inc.), 20(2), 164-169. https://doi-org.wvu.idm.oclc.org/10.1111/ijn.12108

Witte, K., Cameron, K. A., McKeon, J. K., \& Berkowitz, J. M. (1996). Predicting risk behaviors: 
Development and validation of a diagnostic scale. Journal of Health Communication, 1(4), 317-342. https://doi.org/10.1080/108107396127988

World Health Organization. (2021, May). Coronavirus. https://www.who.int/healthtopics/coronavirus\#tab=tab_1

Yzer, M. (2012). Reasoned action theory: Persuasion as belief-based behavior change. In J. P. Dillard \& L. Shen (Eds.), The SAGE handbook of persuasion: Developments in theory and practice (2nd ed., pp. 120-136). Thousand Oaks, CA: SAGE.

Zimmer, Carl, et al. "Novavax's Vaccine Works Well Except on Variant First Found in South Africa." The New York Times, The New York Times, 9 Feb. 2021, www.nytimes.com/live/2021/01/28/world/covid-19-coronavirus. 